\title{
The many faces of adenocarcinoma: a pictorial essay
}

Running title: Many faces of adenocarcinoma

\section{Authors:}

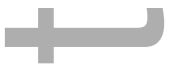

Dr Heather M. Pascoe ${ }^{1}$

Dr Henry C. Knipe ${ }^{1}$

Dr Diane Pascoe

Associate Professor Stefan B. Heinze ${ }^{1}$

${ }^{1}$ Department of Radiology, Royal Melbourne Hospital, University of Melbourne, Parkville, Victoria, Australia.

\section{Corresponding Author:}

Dr Heather Michelle Pascoe

Level 1 Radiology Department, Royal Melbourne Hospital, Grattan St, Parkville, Victoria, Australia, 3050

Email:pasoceh@gmail.com

Phone: 0438674141

Fax: 61393428369

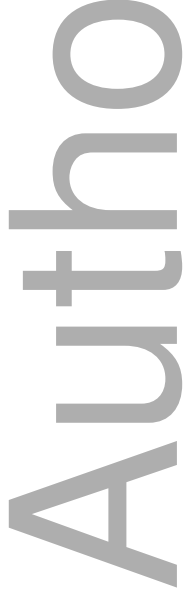

This is the author manuscript accepted for publication and has undergone full peer review but has not been through the copyediting, typesetting, pagination and proofreading process, which may lead to differences between this version and the Version of Record. Please cite this article as doi: $10.1111 / 1754-9485.12779$

This article is protected by copyright. All rights reserved 
DR. HEATHER MICHELLE PASCOE (Orcid ID : 0000-0002-9500-2978)

3

DR. HENRY CHARLES KNIPE (Orcid ID : 0000-0001-8058-2714)

4

5

6

Article type : Radiology Pictorial Essay

7

8

9

Corresponding author mail id:- pascoeh@gmail.com

10

The many faces of lung adenocarcinoma: a pictorial essay

12

Department of Radiology, The Royal Melbourne Hospital, University of Melbourne,

Parkville, Victoria, Australia.

17

Key words:

19

Adenocarcinoma, computed tomography, lung cancer, non neoplastic pulmonary

20 disease

21

22

Abstract

Lung adenocarcinoma has a spectrum of appearances on CT, many of which mimic non-malignant processes. The general radiologist has a major role in guiding the management of abnormalities detected on chest CT and an awareness of these appearances is vital. We describe the protean imaging manifestations of lung adenocarcinoma.

Introduction 
Lung adenocarcinoma has increased in prevalence compared to other subtypes of lung cancer. ${ }^{1}$ Increasing numbers of non-smokers and never-smokers are developing lung adenocarcinoma. $^{2}$

The classification of lung adenocarcinoma was revised in 2011 at which time the term bronchoalveolar carcinoma was removed. Four new terms were introduced to replace this term - adenocarcinoma in situ (AIS), minimally invasive adenocarcinoma (MIA), invasive mucinous adenocarcinoma and lepidic predominant nonmucinous adenocarcinoma. New histopathological subtypes of invasive nonmucinous adenocarcinomas were also introduced (acinar, papillary, micropapillary and solid) and nonmucinous adenocarcinoma is now classified according to the predominant histologic subtype as most tumours consist of a mixture of the subtypes. ${ }^{3}$

Whilst there are 'typical' appearances on CT of each of the above histologies, there is considerable overlap and CT appearances are not pathognomonic: AIS is usually a small ground glass nodule; MIA is typically predominately non-solid but may have a small central solid component; invasive mucinous adenocarcinoma has a varied appearance ranging from completely non-solid to completely solid and may be uni- or multifocal; lepidic predominant nonmucinous adenocarcinoma is usually part-solid but may be non-solid or occasionally contain cystic components, and the other histological subtypes of invasive nonmucinous adenocarcinoma are usually solid but may contain small non-solid components. ${ }^{3}$

Appearances which differ from these typical appearances are common ${ }^{4}$ and importantly may mimic non-malignant processes. Awareness of this, and familiarity with these appearances, becomes especially important when imaging a non- or neversmoking population in which non-malignant causes may be considered as the primary differential diagnosis.

The appearances of lung adenocarcinoma cases in the lung oncology multidisciplinary meetings at our institution reflect this variability. This pictorial review covers the protean imaging manifestations of lung adenocarcinoma.

\section{GROUND GLASS (NON-SOLID) AND PART SOLID NODULES:}

The differential diagnosis for ground glass nodules (Figure 1a) is broad and includes non-malignant conditions such as infection, inflammation and haemorrhage, as well as 
malignant abnormalities including preinvasive (atypical adenomatous hyperplasia and adenocarcinoma in situ) and invasive lesions (minimally invasive adenocarcinoma and invasive adenocarcinoma). ${ }^{4}$

Part solid nodules (Figure 1b) consist of both ground glass and solid components. In malignant lesions, the ground glass component represents lepidic tumour growth. ${ }^{5}$ It is the solid component that represents invasion, and it is proposed that its size rather than the total nodule size is more predictive of prognosis. ${ }^{4}$

\section{SOLID NODULES AND MASSES:}

A solid pulmonary nodule or mass, while non-specific, always carries the possibility of lung malignancy. Despite there being several characteristics suggestive of primary lung malignancy, there are none pathognomonic of adenocarcinoma. Adenocarcinoma manifesting as a solid nodule or mass may be peripheral or central, well-defined (Figure 2a), spiculated (Figure 2b) or lobular and can range in size from millimetres to many centimetres (Figure 2c).

\section{CYSTIC OR BUBBLE-LIKE LUCENCIES:}

Adenocarcinoma can appear as a thin-walled cystic lesion,, ${ }^{6,7}$ (Figure $\mathbf{3}$ and Figure 4a) which may be interpreted as a pulmonary cyst, bleb or bulla. An awareness that adenocarcinoma can begin with this appearance is important as over time these lesions can increase in size and develop wall thickening and solid components (Figure 4), suspicious for the development of an invasive component. ${ }^{6,7}$

'Bubble-like' lucencies can occur within pulmonary nodules and regions of consolidation due to focal bronchiectasis ${ }^{6,8}$ (Figure 6a) and such lesions may be incorrectly dismissed as regions of previous inflammation. ${ }^{8}$

\section{VARIABLE GROWTH RATE:}

Adenocarcinoma (Figure 5) is typically slower-growing than other lung cancer subtypes and may be stable or grow very slowly for years, mimicking benign pathology such as granulomas. ${ }^{9}$ Importantly, however, past growth rate is not a predictor of future 
growth rate, with adenocarcinoma in particular capable of undergoing sudden or unpredictable rapid growth even when the initial growth rate has been slow. ${ }^{10}$

\section{MULTIFOCAL:}

Multifocal lung adenocarcinoma is less common than solitary adenocarcinoma. ${ }^{11}$ The tumours may be found in a single lobe of the lung, multiple lobes of one lung or multiple lobes of both lungs (Figure 6). ${ }^{6}$ The lesions are often at different stages along the adenocarcinoma spectrum ranging from preinvasive (e.g. ground glass nodules) to invasive (e.g. solid nodules), potentially giving rise to different appearances of adenocarcinoma within the single patient.

\section{CALCIFICATION:}

Calcification within lung lesions is most commonly a sign of benignity, but may uncommonly be seen in primary lung tumours (Figure 7). The pattern of calcification does not predict the histologic subtype but calcification is more commonly seen in adenocarcinoma than other lung cancer subtypes. ${ }^{12}$

\section{CAVITATION:}

The differential of cavitating lung lesions is broad including infection (e.g. tuberculosis, pulmonary abscess) and malignancy, most commonly squamous cell carcinoma. Cavitating lung adenocarcinoma also occurs (Figure 8) but this entity is less well known. The clinical presentation and imaging features of cavitating infection and malignancy often overlap.

\section{MIMIC PNEUMONIA:}

Air bronchograms are a key diagnostic feature of infective consolidation; the primary diagnosis for an area of airspace opacity with air bronchograms should be pneumonia. Lung adenocarcinoma can, however, display both of these features in a pattern very similar to infection. Solid and part solid nodules, as well as regions of consolidation, commonly also have air bronchograms (Figure 9). The presence of air bronchograms within a part solid nodule indicates an increased likelihood of invasion. ${ }^{4}$ When present 
125 in a solid nodule or region of consolidation suspected of being malignant, air

126 bronchograms are suggestive of a well-differentiated tumour. ${ }^{6}$

127 Lobar or sublobar regions of consolidation and/or ground glass opacity replacement

128 can mimic lobar pneumonia (Figure 10a and 10b). Depending on the distribution of the 129 pulmonary changes, they may also mimic aspiration pneumonitis/pneumonia (Figure

130 11).

131

132

MIMIC FUNGAL INFECTION:

133 The "halo sign" consists of a nodule with a solid central component surrounded by

134 ground glass opacity (Figure 12). While it is often thought of as typical for

135 angioinvasive fungal infection, several other pathological processes can cause this

136 appearance including vasculitis, organising pneumonia, metastasis and

137 adenocarcinoma. Adenocarcinoma has been described as the most common cause for

138 the halo sign in immunocompetent patients. ${ }^{13}$

140 MIMIC OTHER THORACIC MALIGNANCIES:

141 The most likely diagnosis for widespread mediastinal lymphadenopathy without a

142 dominant lung lesion is either small cell lung cancer or lymphoma. The differential

143 diagnosis includes primary lung adenocarcinoma, which can occasionally have this

144 appearance (Figure 13). The diagnosis, which can only be made on biopsy, is crucial

145 as the treatment and prognosis differ substantially for each of these conditions.

MIMIC INFARCT:

148 Classically, pulmonary infarction presents at CT as a solitary wedge-shaped peripheral

149 opacity, however, appearances can be variable depending on the underlying cause

150 and timing of imaging from symptom onset. Clinical and radiological characteristics of

151 pulmonary infarction and lung cancer overlap, and hence these conditions may mimic

152 each other (Figure 14). ${ }^{14}$

MIMIC SCAR:

This article is protected by copyright. All rights reserved 
Lung carcinoma arising in a region of scar tissue can be easily overlooked as chronic scarring (Figure 15); the majority of scar carcinomas are adenocarcinoma. ${ }^{15}$ Careful comparison with previous imaging is the key to detecting changes within a region of scarring. The CT features are enlargement of the lesion, surrounding ground glass opacity and well-defined borders of the lesion. While these features raise the suspicion of scar carcinoma, chronic inflammation or recurrent tuberculosis can give a similar appearance. $^{15}$

\section{Conclusion}

Lung adenocarcinoma has a wide variety of appearances, several of which are identical to, or closely mimic, non-malignant processes. This is especially important as non- and never smokers become more numerous in this patient population.

\section{References}

1. Meza R, Meernik C, Jeon J, Cote ML. Lung cancer incidence trends by gender, race and histology in the United States, 1973-2010. PLoS One. 2015 Mar 30;10(3):e0121323.

2. Wakelee HA, Chang ET, Gomez SL et al. Lung cancer incidence in never smokers. J Clin Oncol. 2007 Feb 10;25(5):472-8.

3. Austin JHM, Garg K, Aberle D et al. Radiologic implications of the 2011 classification of adenocarcinoma of the lung. Radiology. 2013 Jan;266(1):62-71.

4. Gardiner N, Jogai S, Wallis A. The revised lung adenocarcinoma classification-an imaging guide. J Thorac Dis. 2014 Oct;6(Suppl 5):S537-46.

5. Christiani DC, Pao W, DeMartini JC et al. BAC Consensus Conference, November 4-6, 2004: Epidemiology, Pathogenesis, and Preclinical Models. J Thorac Oncol. 2006;1(9):S27.

6. Gaikwad A, Gupta A, Hare S et al. Primary adenocarcinoma of lung: a pictorial review of recent updates. Eur J Radiol. 2012 Dec;81(12):4146-55.

7. Yoshida $T$, Harada $T$, Fuke $S$ et al. Lung adenocarcinoma presenting with enlarged and multiloculated cystic lesions over 2 years. Respir Care. 2004 Dec;49(12):1522-4.

8. Saito $\mathrm{H}$, Yamada $\mathrm{K}$, Hamanaka $\mathrm{N}$ et al. Initial findings and progression of lung adenocarcinoma on serial computed tomography scans. J Comput Assist Tomogr. 2009

This article is protected by copyright. All rights reserved 
Jan;33(1):42-8.

9. Infante M, Berghmans T, Heuvelmans MA, Hillerdal G, Oudkerk M. Slow-growing lung cancer as an emerging entity: from screening to clinical management. Eur Respir J. 2013 Dec;42(6):1706-22.

10. Lindell RM, Hartman TE, Swensen SJ, Jett JR, Midthun DE, Mandrekar JN. 5-year lung cancer screening experience: growth curves of 18 lung cancers compared to histologic type, CT attenuation, stage, survival, and size. Chest. 2009 Dec;136(6):1586-95.

11. Travis WD, Brambilla E, Noguchi M et al. International Association for the Study of Lung Cancer/American Thoracic Society/European Respiratory Society international multidisciplinary classification of lung adenocarcinoma. J Thorac Oncol. 2011 Feb;6(2):244-85.

12. Grewal RG, Austin JH. CT demonstration of calcification in carcinoma of the lung. J Comput Assist Tomogr. 1994 Nov;18(6):867-71.

13. Kim Y, Lee KS, Jung KJ, Han J, Kim JS, Suh JS. Halo sign on high resolution CT: findings in spectrum of pulmonary diseases with pathologic correlation. J Comput Assist Tomogr. 1999 Jul;23(4):622-6.

14. George CJ, Tazelaar HD, Swensen SJ, Ryu JH. Clinicoradiological features of pulmonary infarctions mimicking lung cancer. Mayo Clin Proc. 2004 Jul;79(7):895-8.

15. Gao F, Ge X, Li M et al. CT features of lung scar cancer. J Thorac Dis. 2015 Mar;7(3):27380.
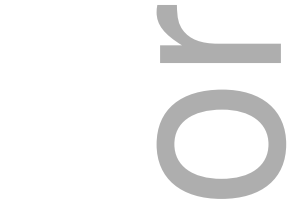

\section{Figure Legends:}

Figure 1: Solid and part solid nodules on CT:
A) Pure ground glass opacity nodule - the most common appearance of adenocarcinoma in situ.
B) Part solid nodule - the presence of solid components in part solid nodules is consistent with an invasive component. This nodule was moderately differentiated adenocarcinoma at histopathology. 
217 Figure 2: Adenocarcinoma presenting as solid lesions. A) Solid peripheral nodule with

218 lobulated margins, B) Peripheral spiculated nodule and C) Large solid mass.

219

220 Figure $3(\mathrm{~A}$ and $\mathrm{B})$ : Moderately differentiated adenocarcinoma presenting as a thin

221 walled multiseptated cystic lesion with surrounding ground glass opacity which had

222 increased in size over 18 months.

Figure 4: Progression of a small cystic lesion to invasive adenocarcinoma in a 71 year old female.

(A) A small cystic lesion in the left lower lobe which over 24 months developed a small central solid component (B). After a further 21 months $(C)$ the nodule is completely solid and has increased in size.

Figure 5: Progression of a small solid nodule to invasive adenocarcinoma. In this 85 year old non smoker, a small solid nodule $(A)$ demonstrated minimal growth over 19 months (B). On CT 7 months later (C) the nodule had grown substantially, highly suspicious for an invasive lesion. The new left pleural effusion was drained and cytology was positive for adenocarcinoma.

Figure 6: Multifocal adenocarcinoma in a 63 year old smoker

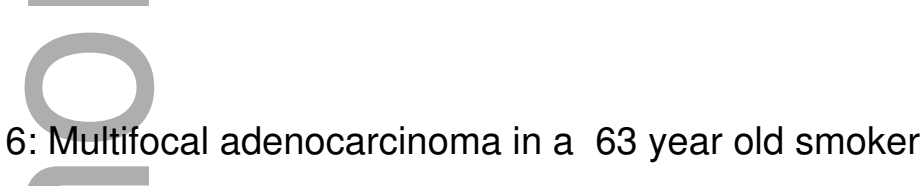

A) Bubbly nodule in the anterior right upper lobe and a solid nodule with internal bubble-like lucencies in the left upper lobe. The left upper lobe nodule is biopsy proven well differentiated adenocarcinoma.

B) Multiple ground glass nodules in the lung apices are likely either at preinvasive or minimally invasive stages of the adenocarcinoma spectrum.

Figure 7: Adenocarcinoma in two different patients ( $A$ and $B$ ) presenting as large solid central masses with internal calcifications. 
Figure 8: Thick walled, cavitating right apical lesion in a 81 year old Chinese patient presenting with fevers and rigors is highly suspicious for tuberculosis. Bronchial washings confirmed adenocarcinoma.

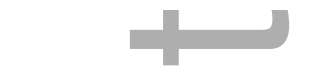

Figure 9: Focal consolidation in the right lower lobe with air bronchograms in a 71 year old non smoker who presented with a cough and intermittent fevers. The consolidation failed to resolve on serial CT examinations and bronchial brushings confirmed adenocarcinoma.

Figure 10: Adenocarcinoma mimicking lobar pneumonia:

(A) Diffuse ground glass change in the superior right lower lobe of a 76 year old presenting with productive cough and weight loss. Appearances are consistent with pneumonia. Bronchial brushings confirmed adenocarcinoma (B) Diffuse ground glass change in the anterior left upper lobe of a 68 year old smoker with persistent cough was initially thought to represent pneumonia. The changes persisted on serial CT examinations and there was no clinical response to antibiotics. Bronchial brushings confirmed adenocarcinoma.

Figure 11: Right lower lobe adenocarcinoma mimicking the appearance of aspiration in a 64 year old non smoker. The location of the consolidation at the right lung base and presence of a moderate sized hiatus hernia containing food debris (arrow), although strongly suggestive of aspiration pneumonitis, were misleading.

Figure 12: Adenocarcinoma presenting as a CT halo sign in a 71 year old ex-smoker. Many pathological processes can cause the halo sign however it is often thought of as typical for angioinvasive fungal infection.

Figure 13: Extensive mediastinal and hilar lymphadenopathy identified incidentally in a 64 year old patient, was suspected to represent either small cell lung carcinoma or lymphoma. Transbronchial needle aspiration and bronchial washings confirmed adenocarcinoma.

This article is protected by copyright. All rights reserved 
277 Figure 14: Moderately differentiated adenocarcinoma presenting as a wedge-shaped

278 region of peripheral consolidation in a 64 year old current smoker. These features

279 mimic the appearance of a pulmonary infarct.

280

281 Figure 15: Spiculated reticular lesion at the left lung apex of a 72 year old female (A).

282 This proved to be adenocarcinoma but could easily be attributed to chronic scarring. $A$

$2837 \mathrm{~mm}$ nodular component at the inferior margin (arrow in B) raised the suspicion of 284 malignancy.

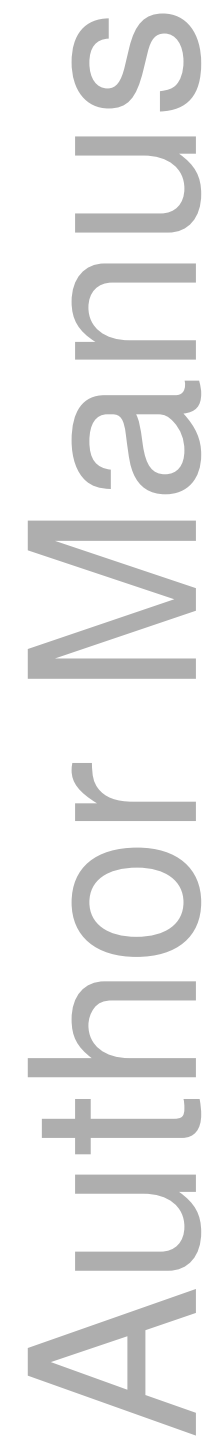

This article is protected by copyright. All rights reserved 

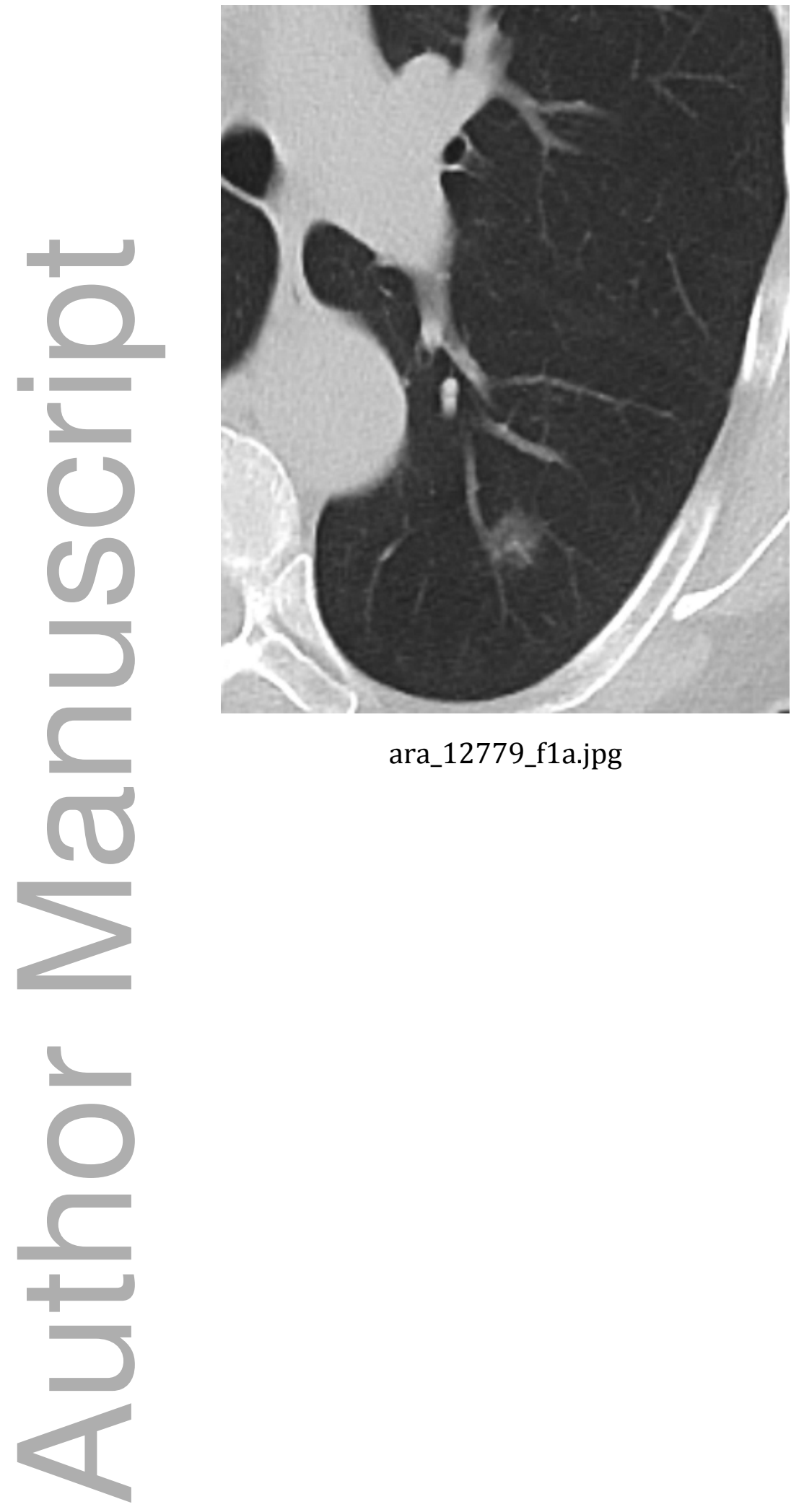

ara_12779_f1a.jpg 

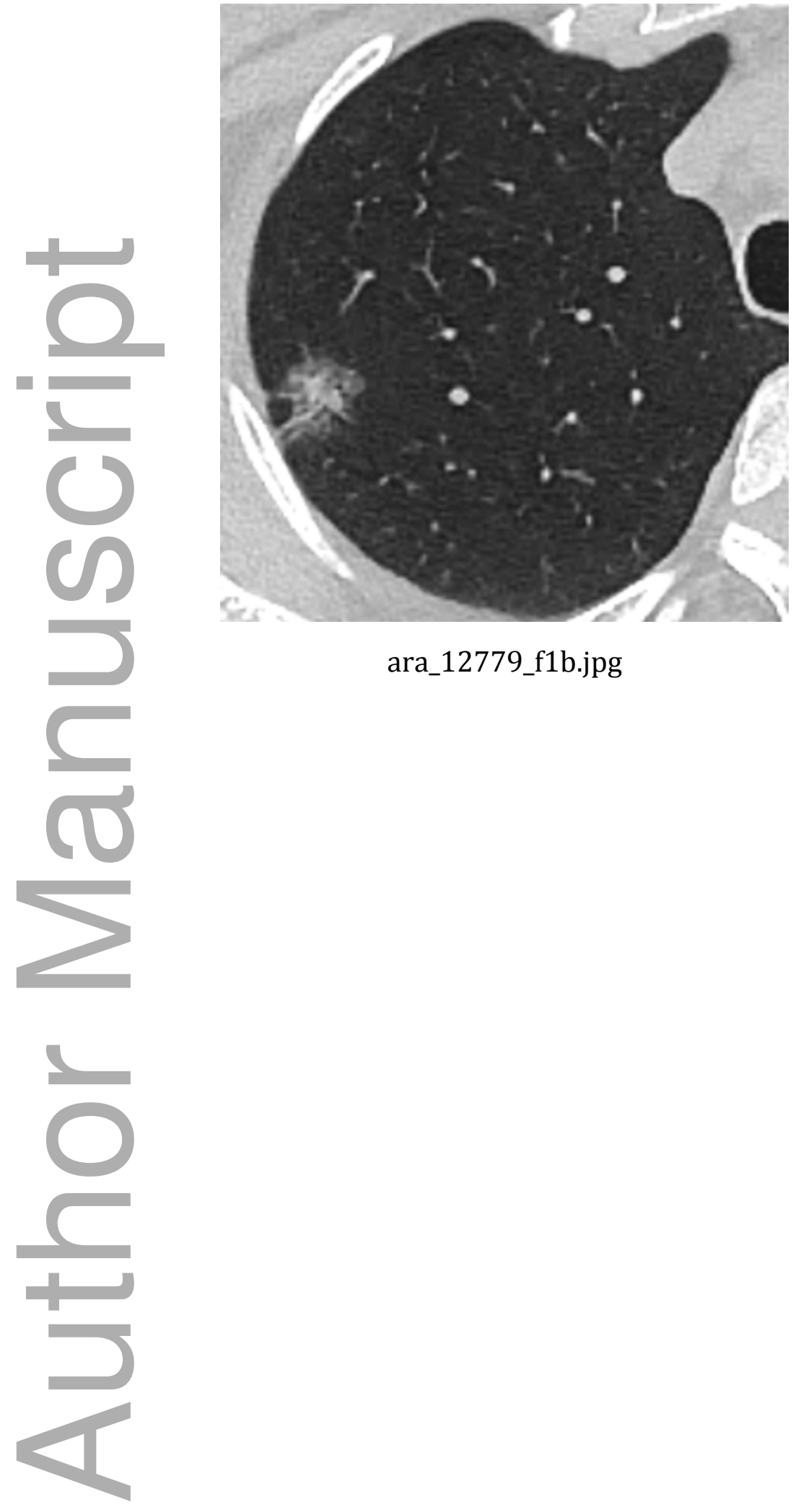

ara_12779_f1b.jpg 

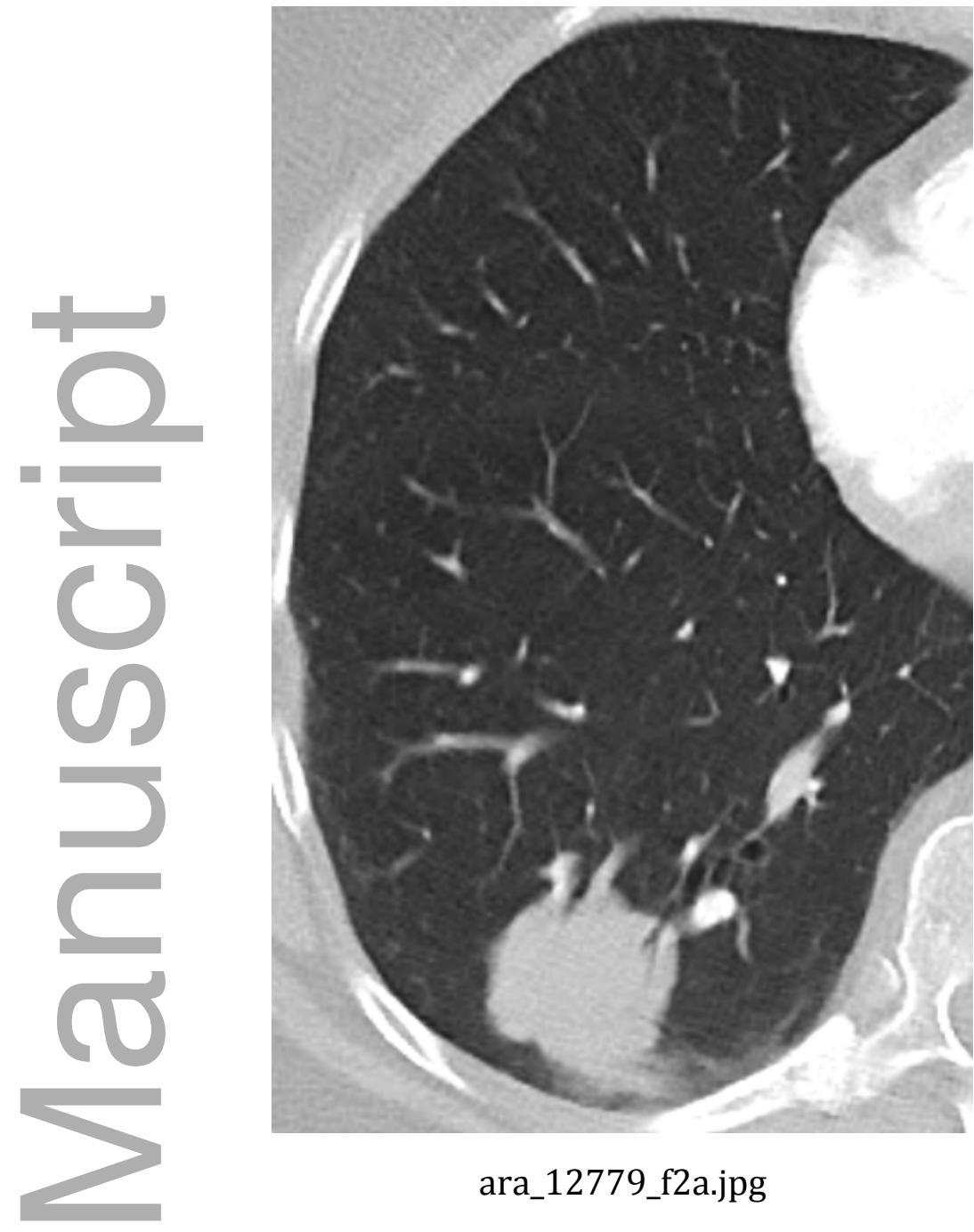

ara_12779_f2a.jpg

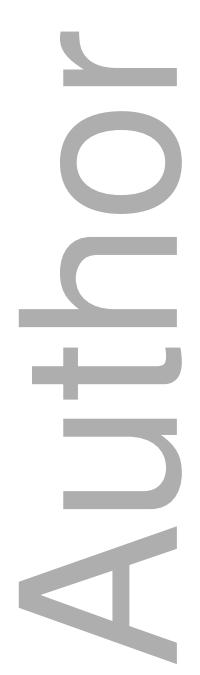



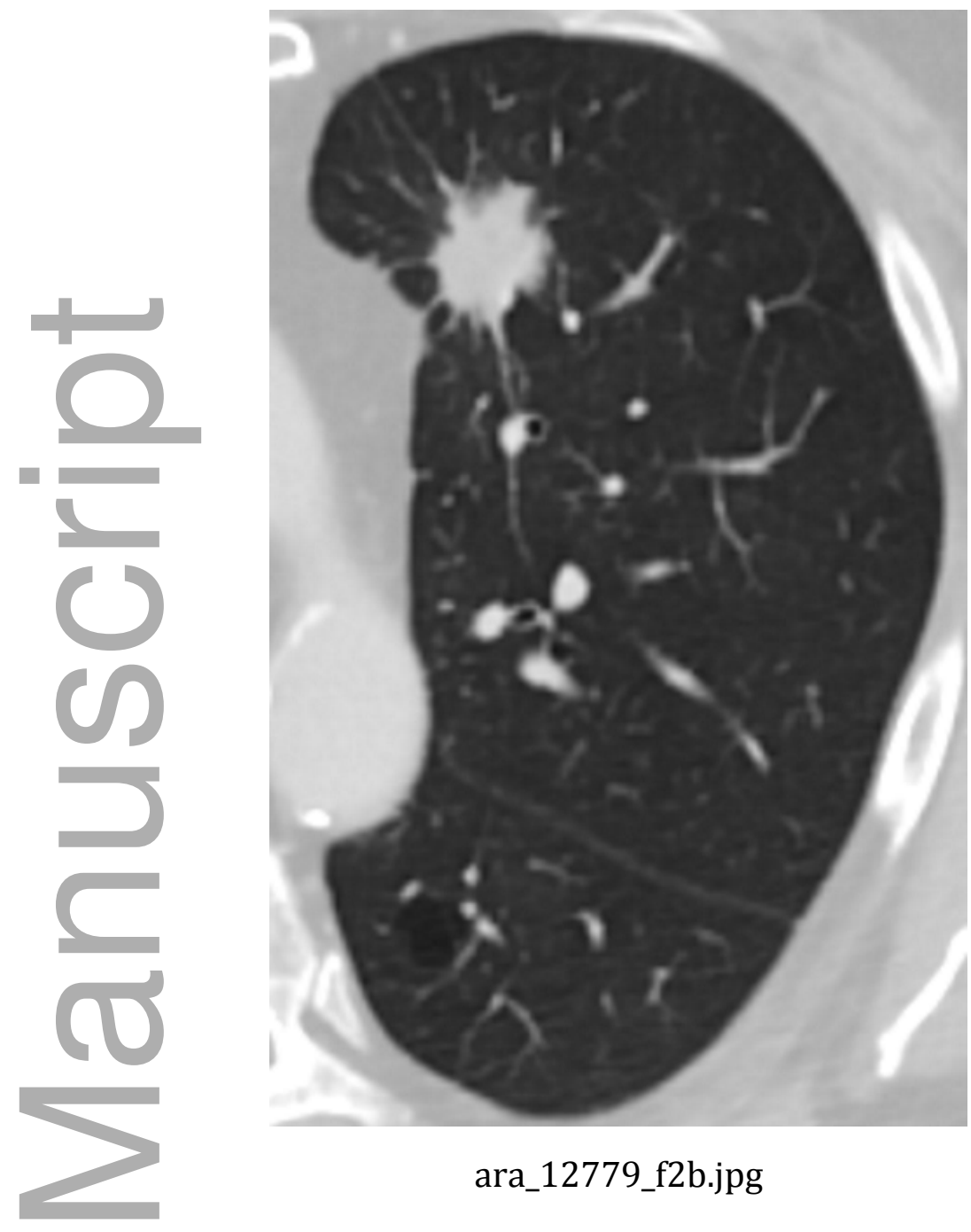

ara_12779_f2b.jpg

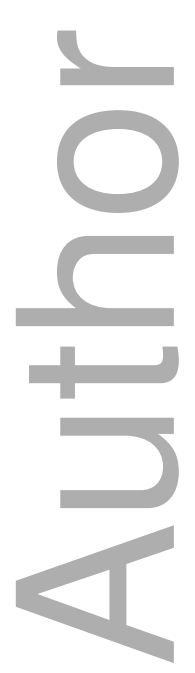



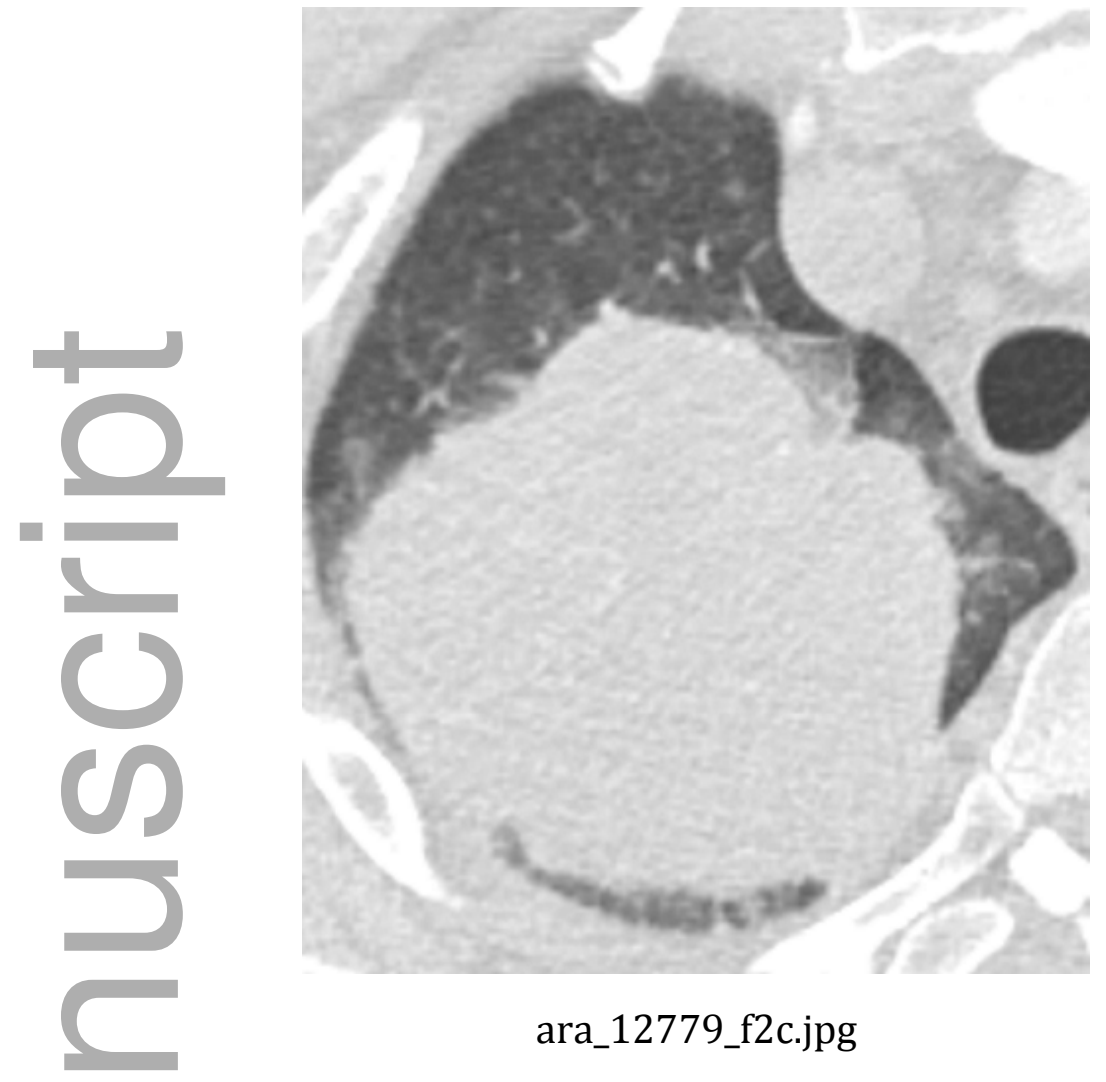

ara_12779_f2c.jpg
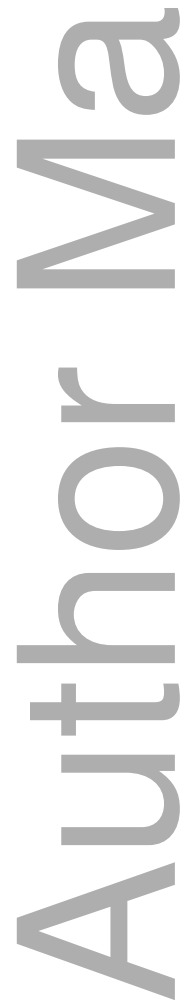

This article is protected by copyright. All rights reserved 

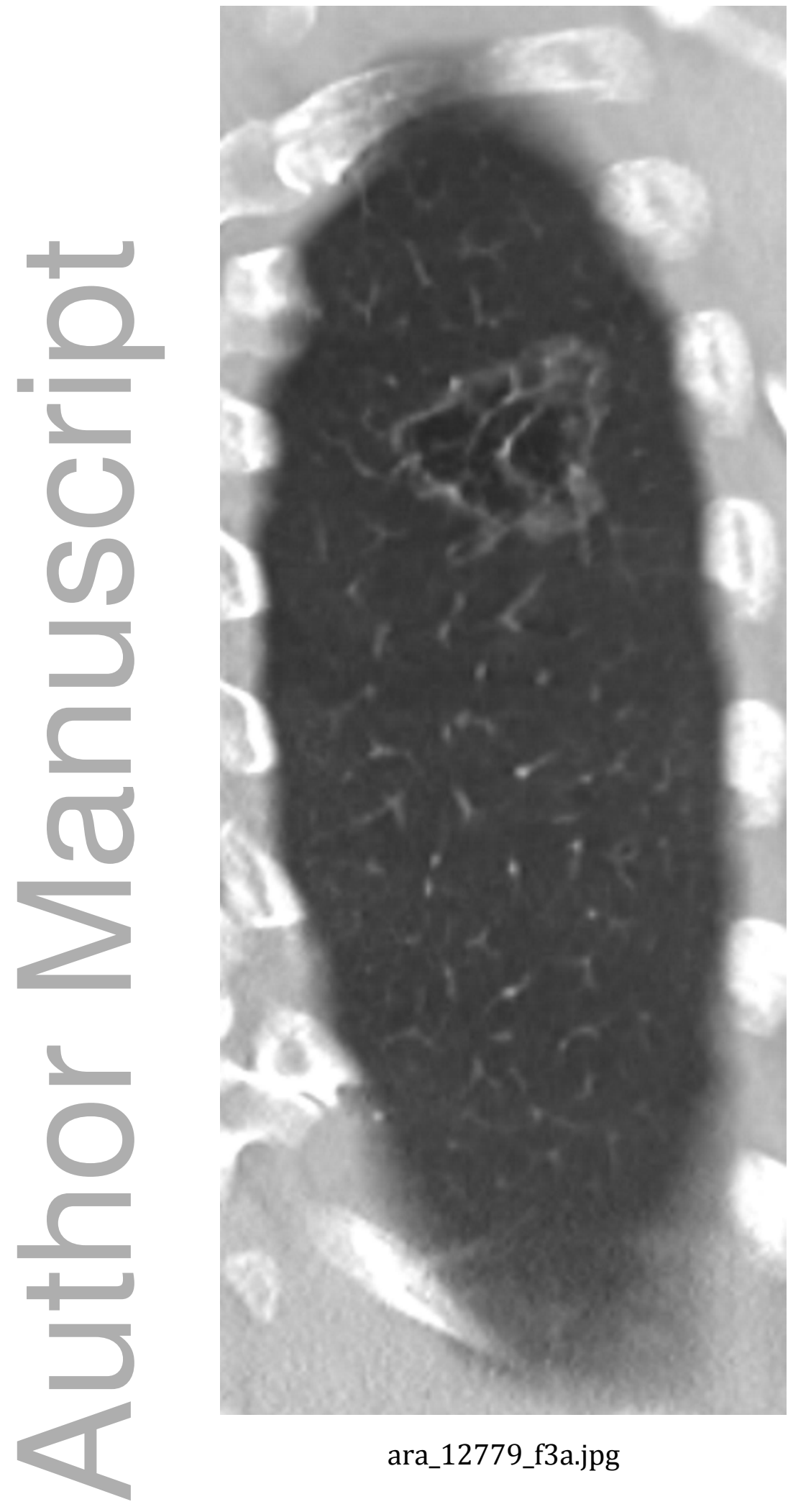

ara_12779_f3a.jpg 


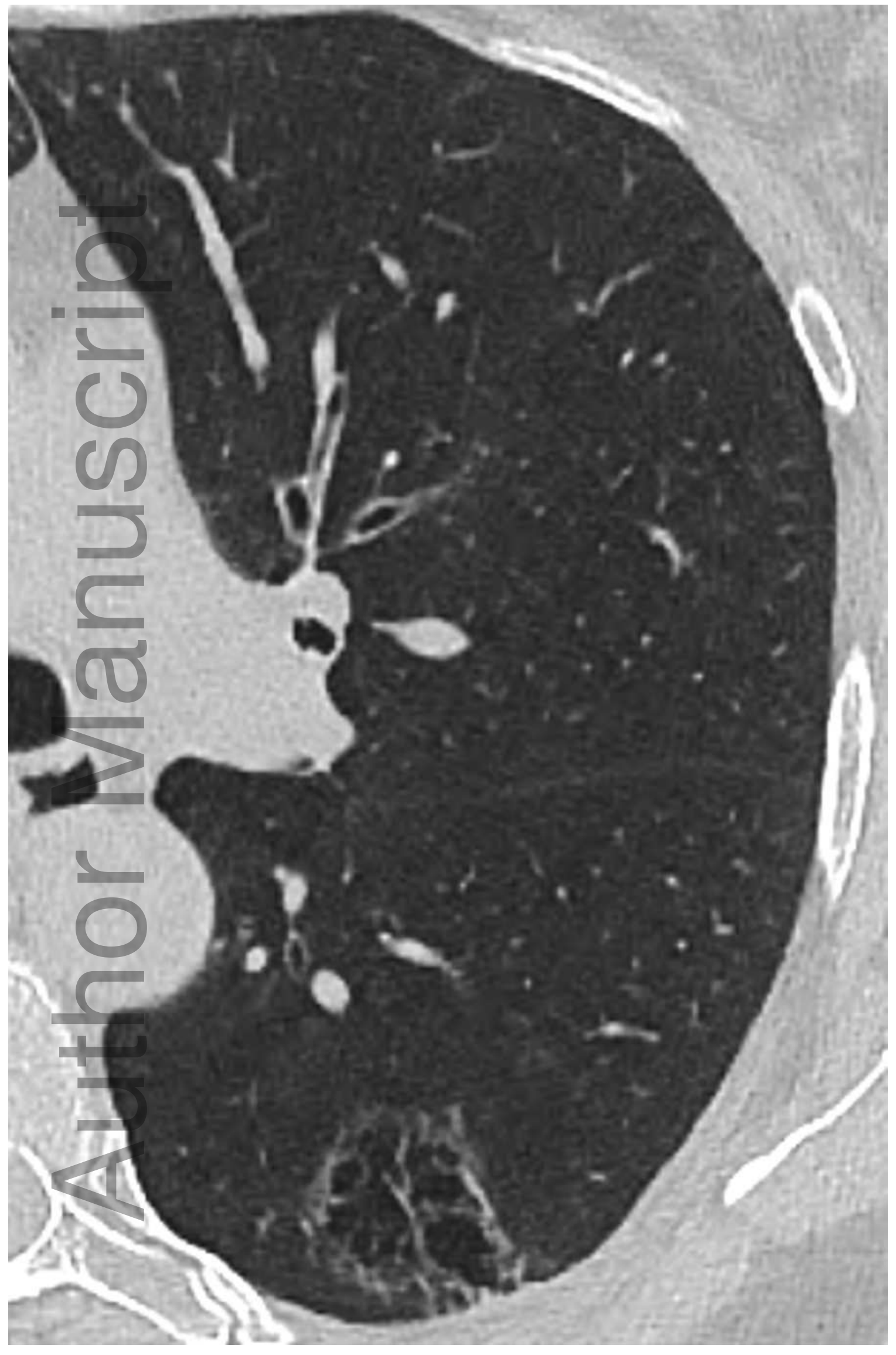

ara_12779_f3b.jpg

This article is protected by copyright. All rights reserved 

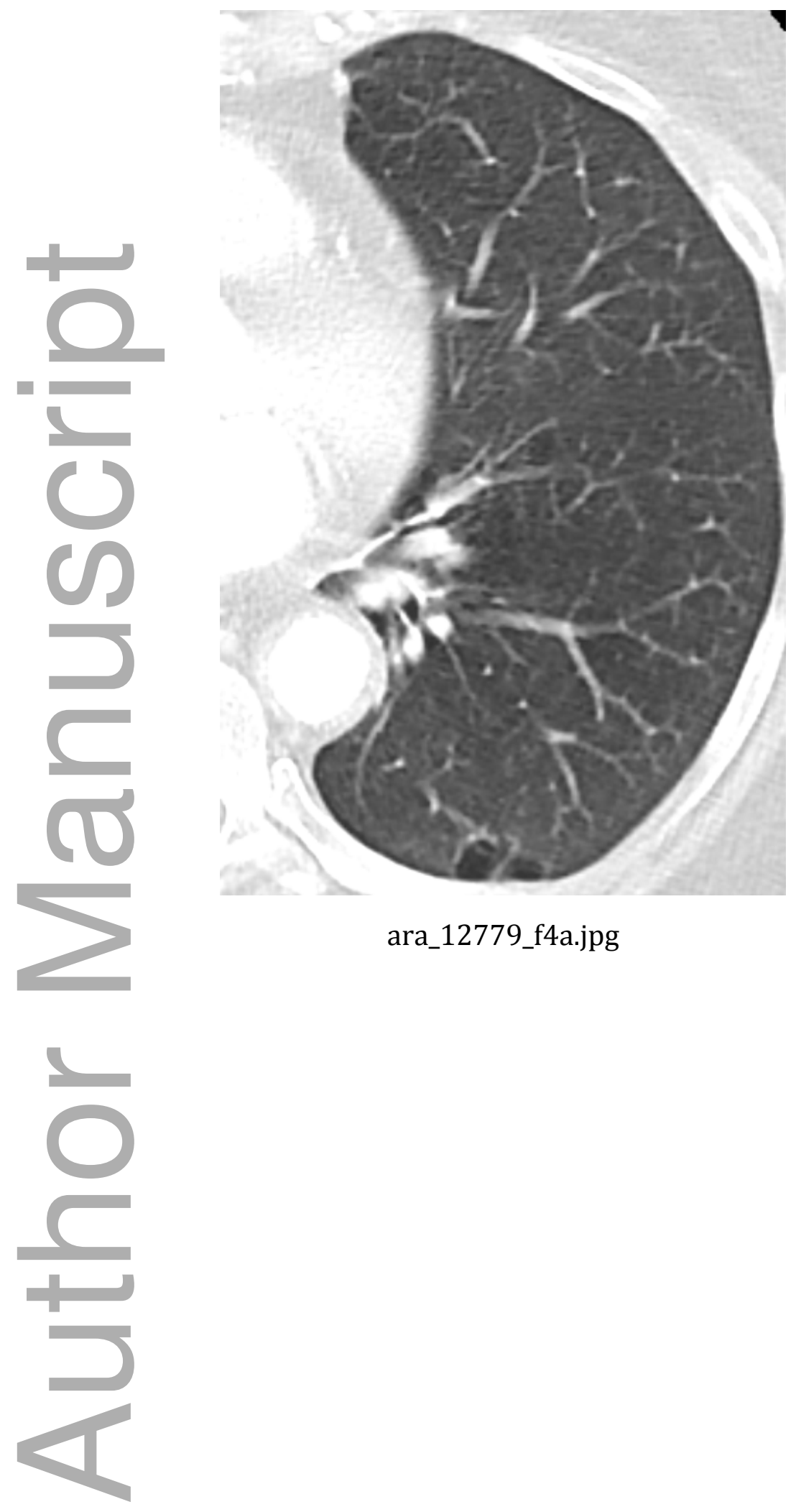

ara_12779_f4a.jpg 

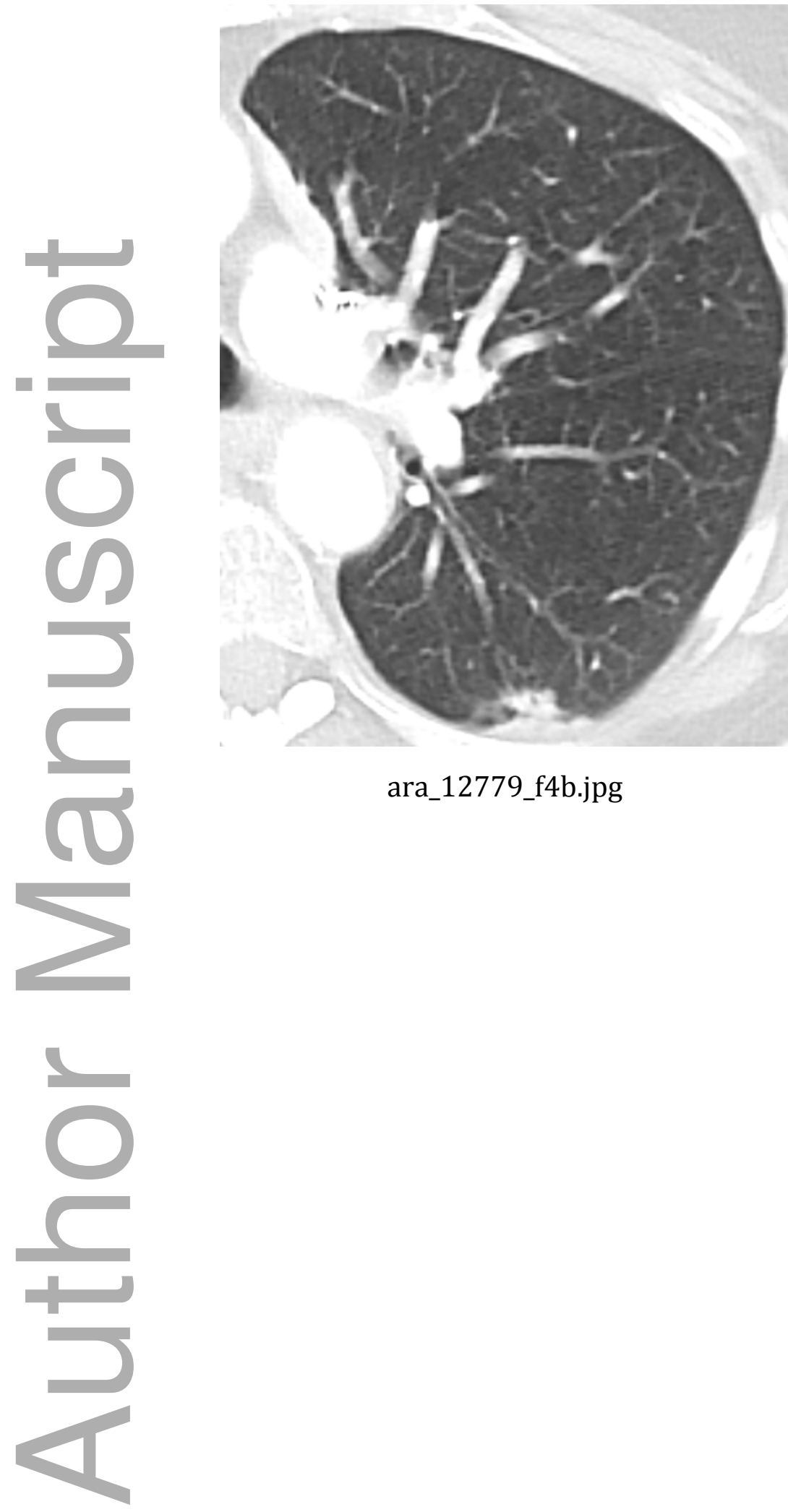

ara_12779_f4b.jpg 


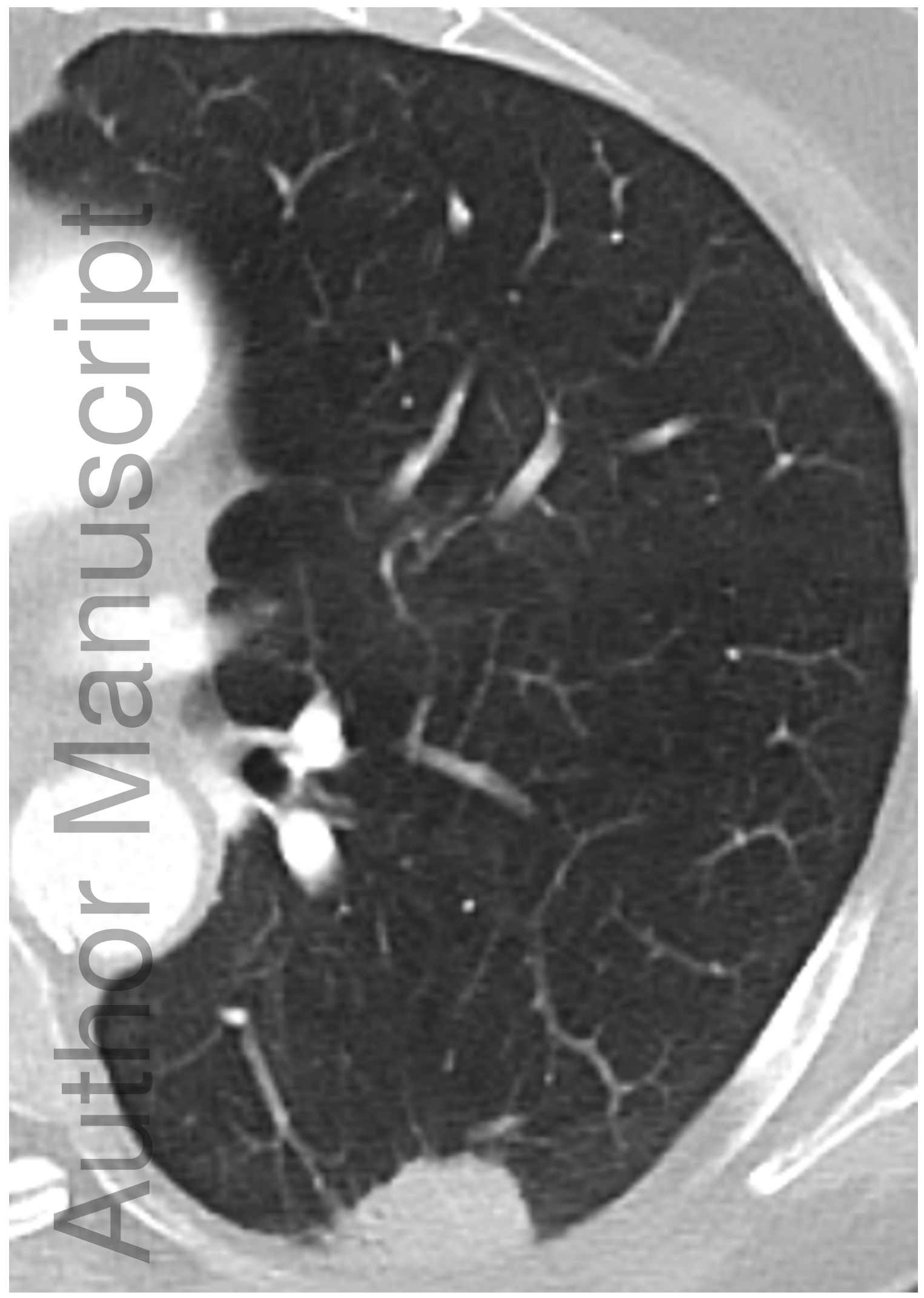

ara_12779_f4c.jpg

This article is protected by copyright. All rights reserved 

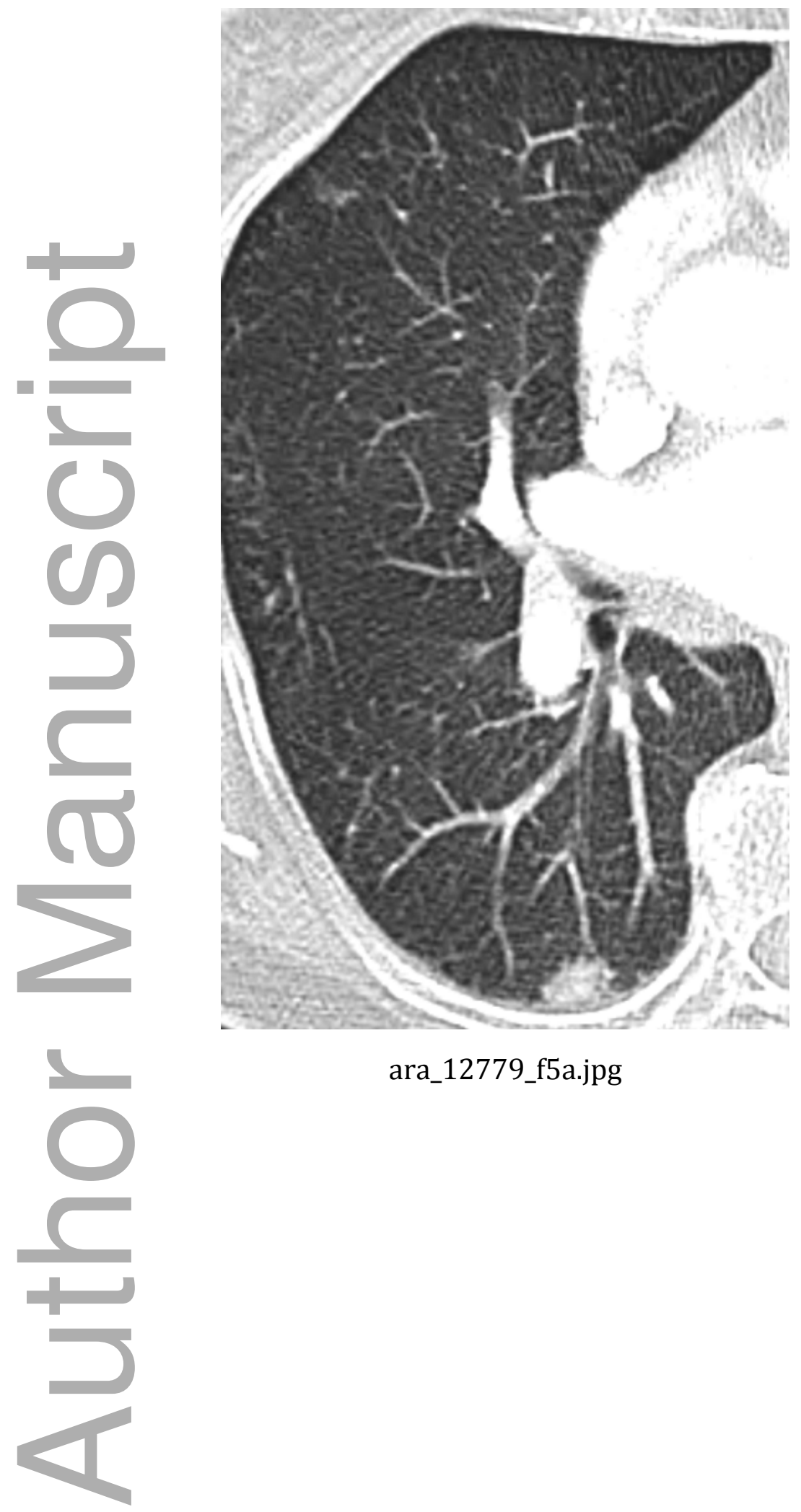

ara_12779_f5a.jpg 

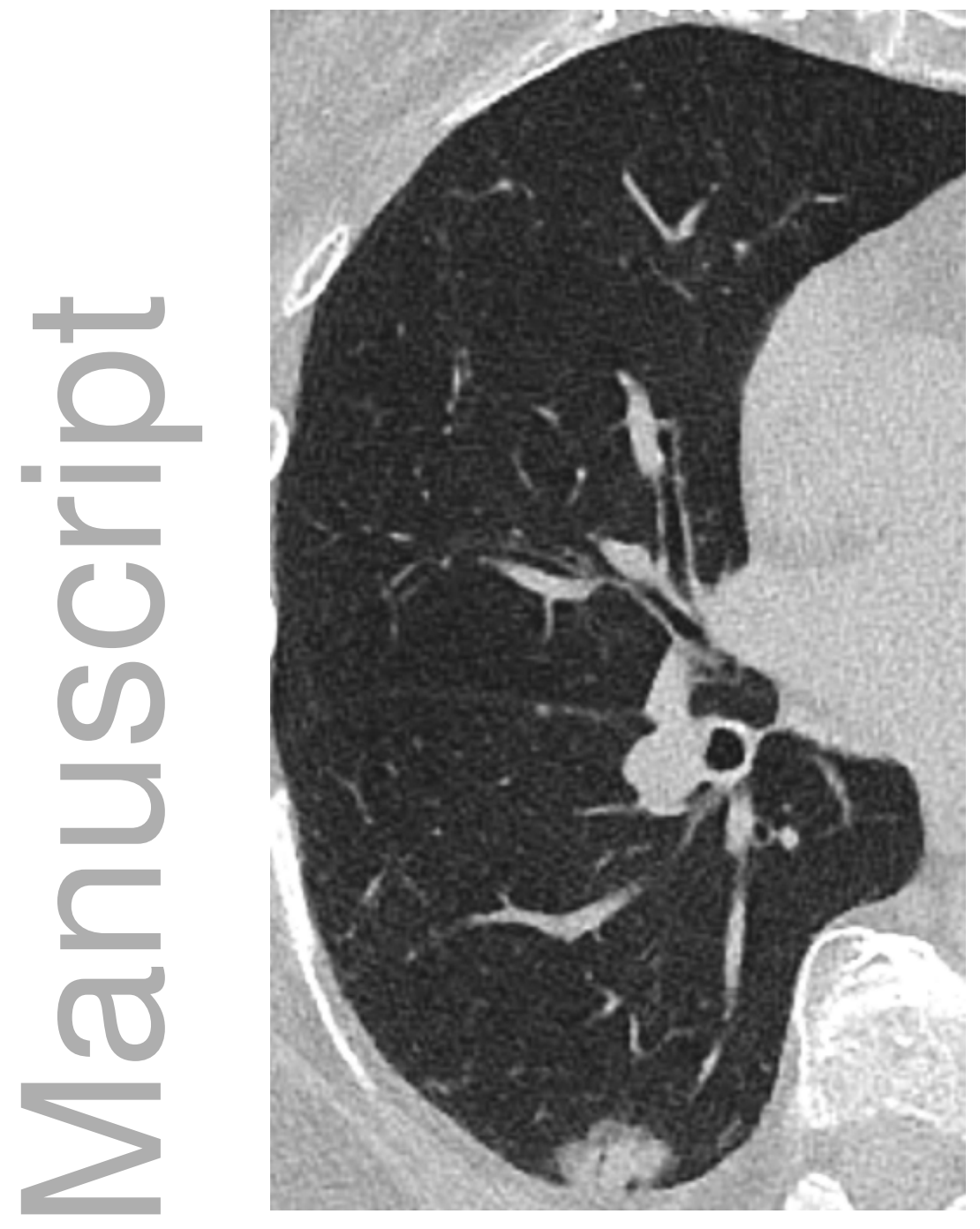

ara_12779_f5b.jpg

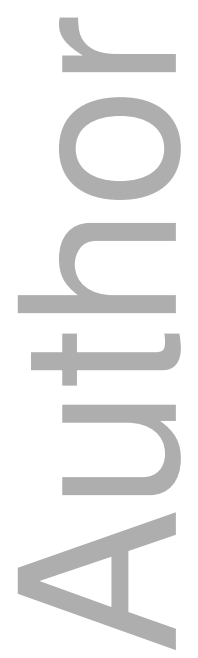



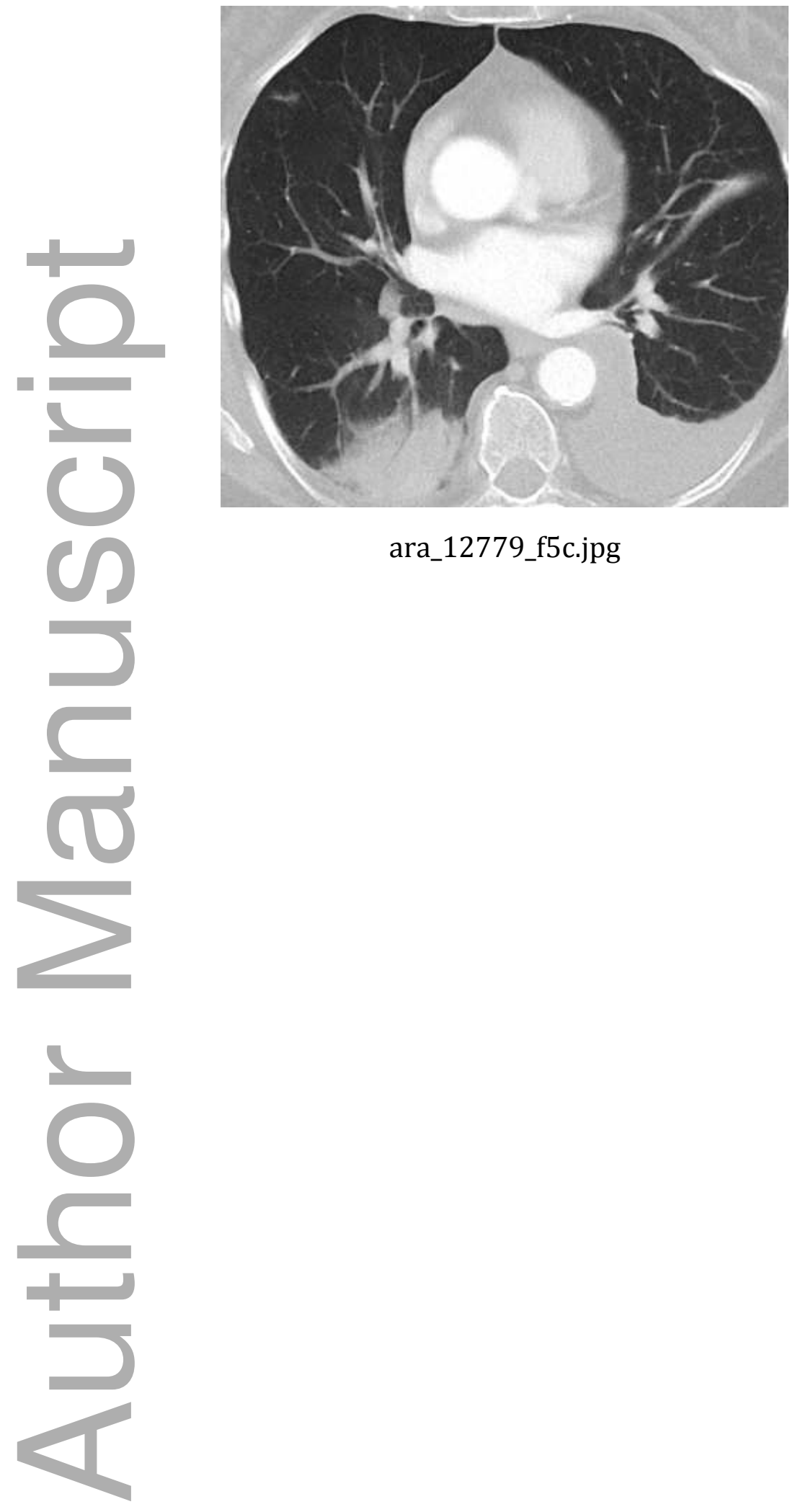

ara_12779_f5c.jpg 

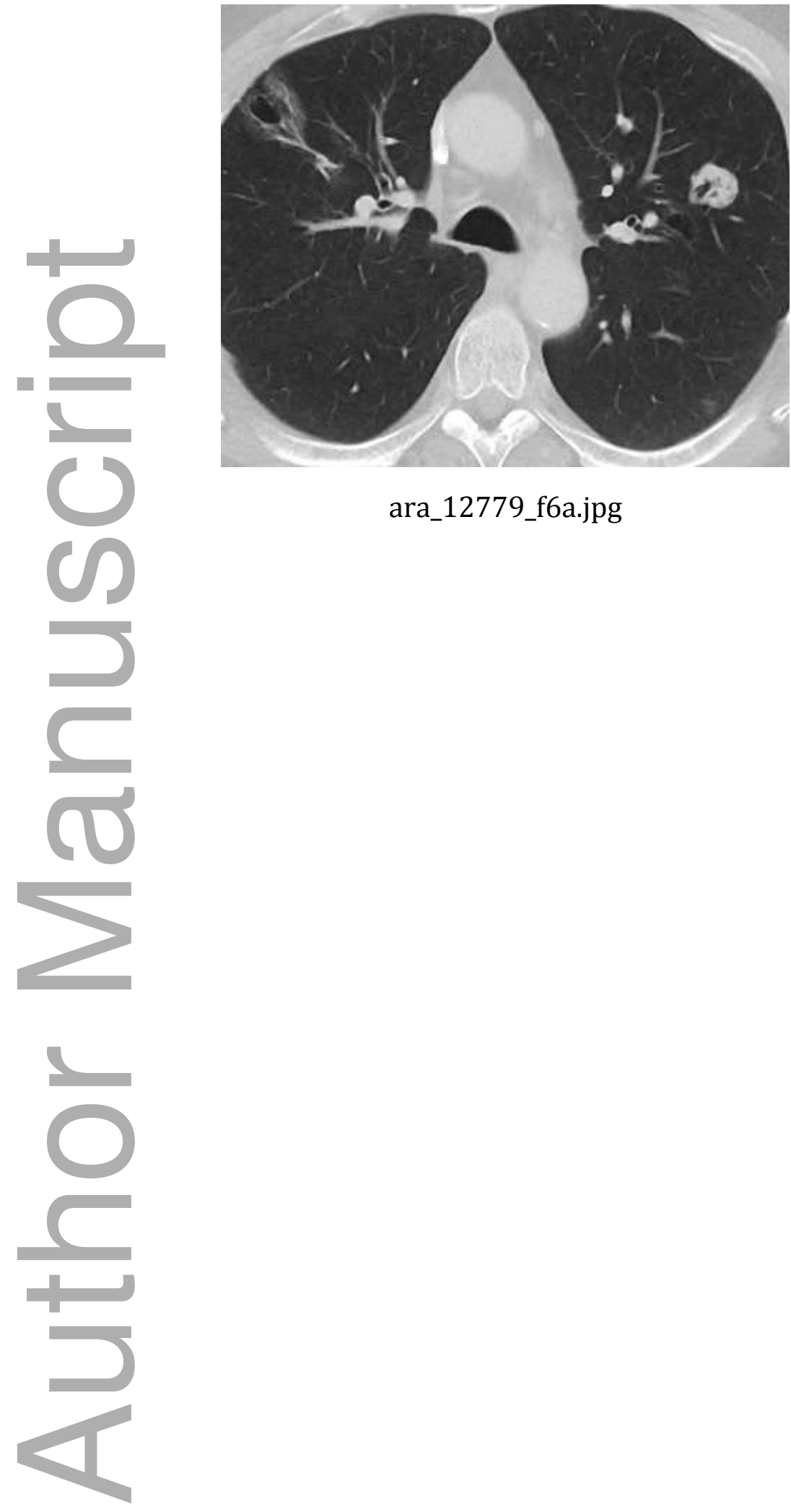

ara_12779_f6a.jpg 

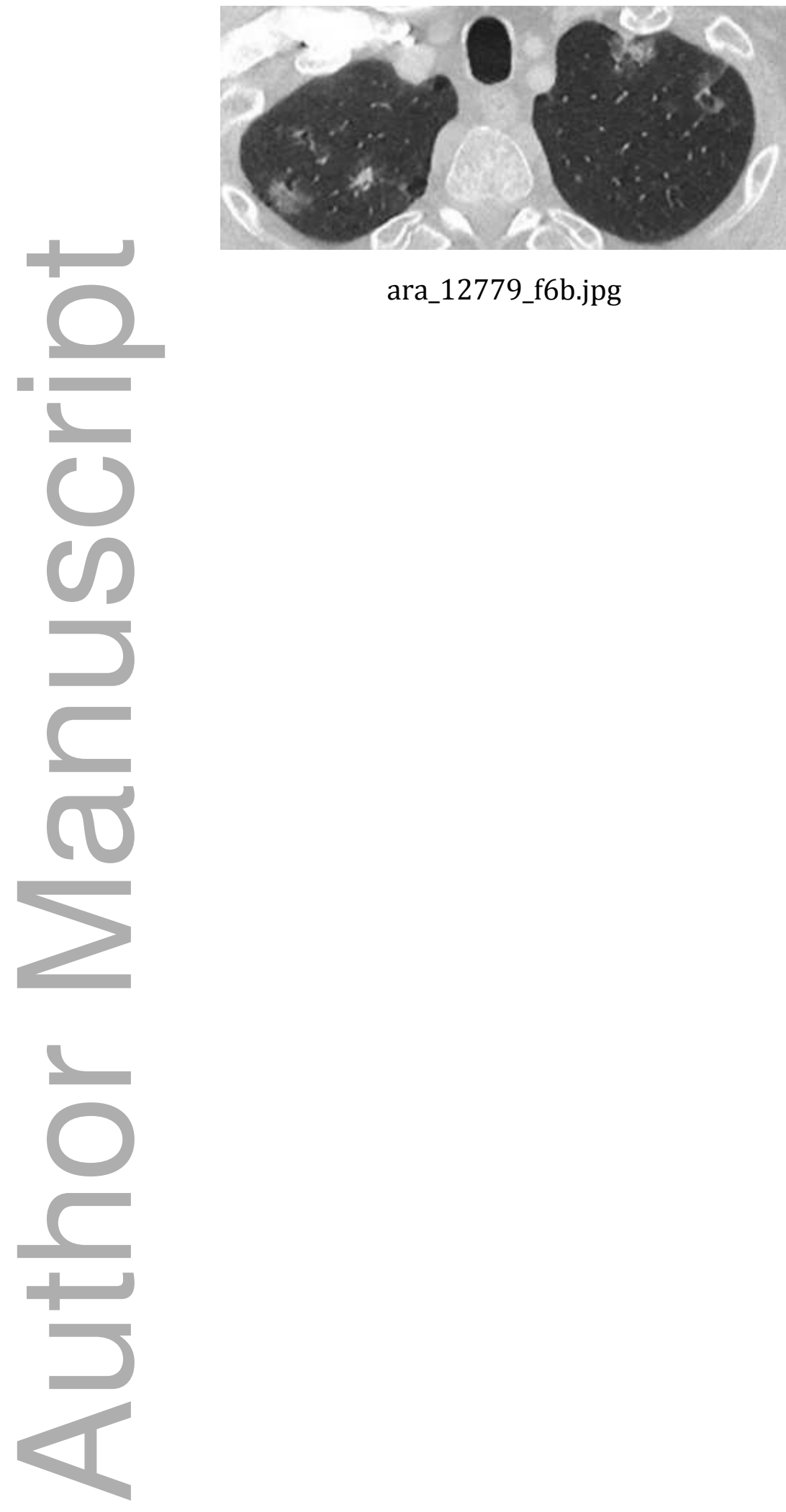

ara_12779_f6b.jpg 

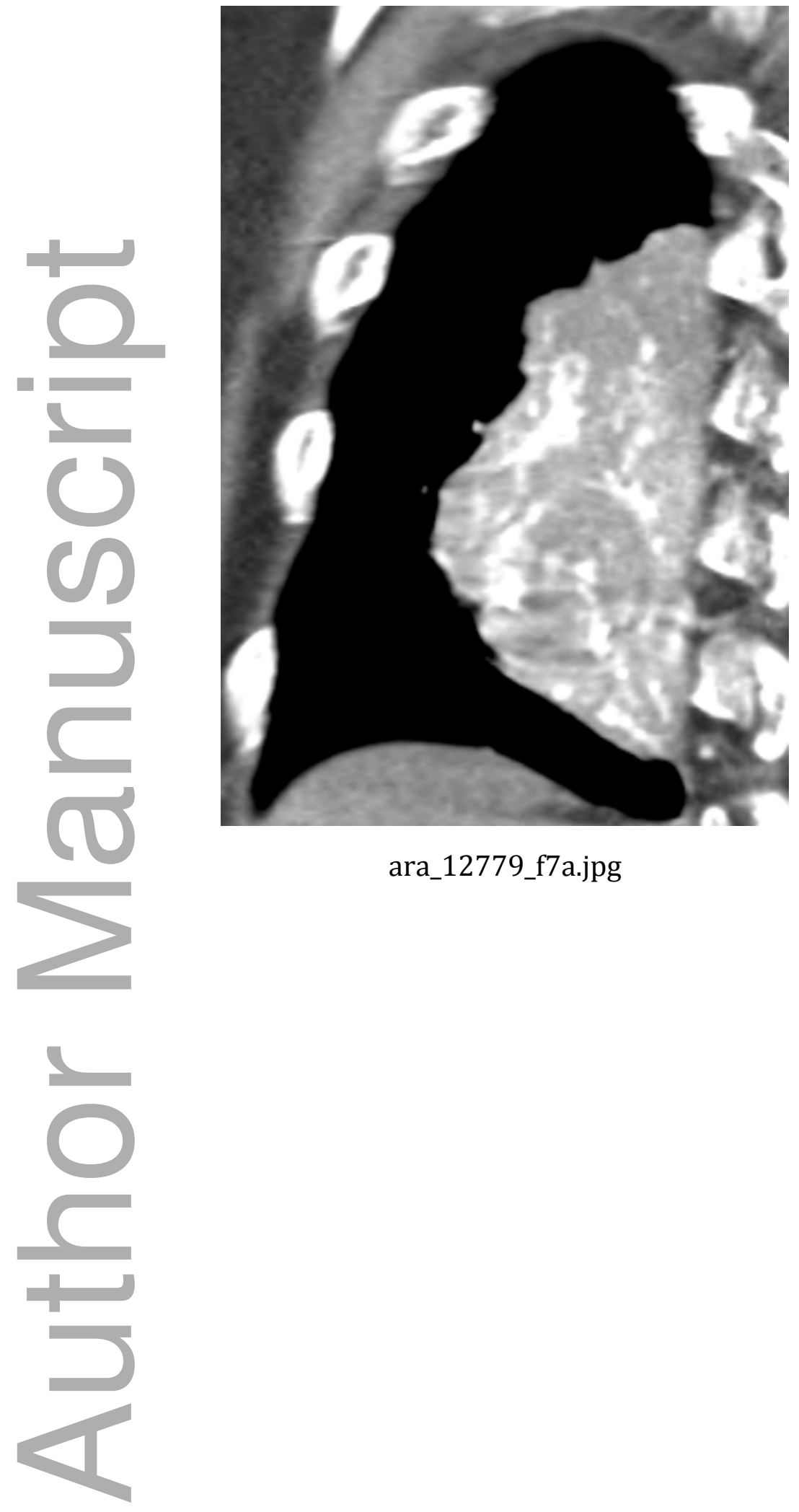

This article is protected by copyright. All rights reserved 

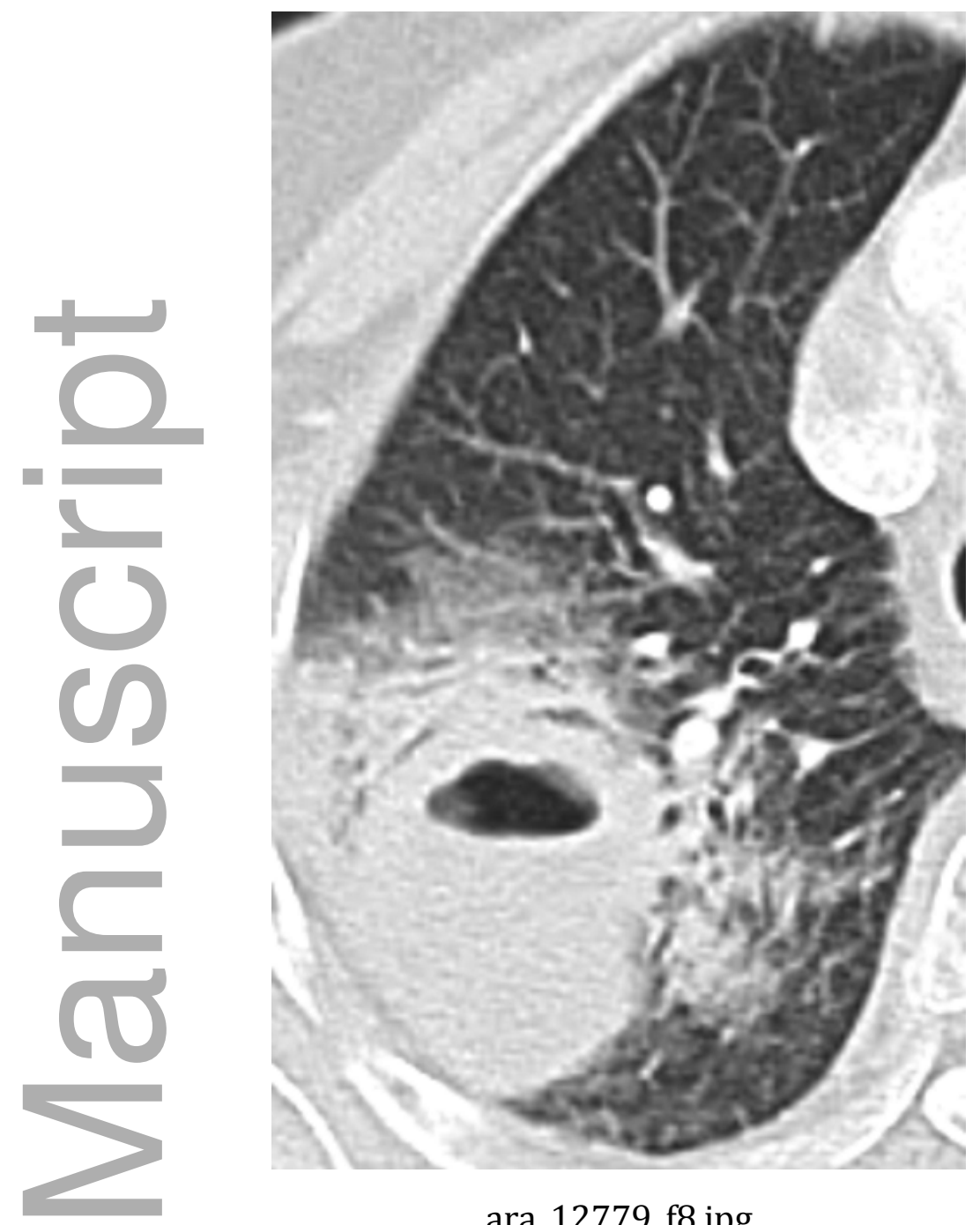

ara_12779_f8.jpg

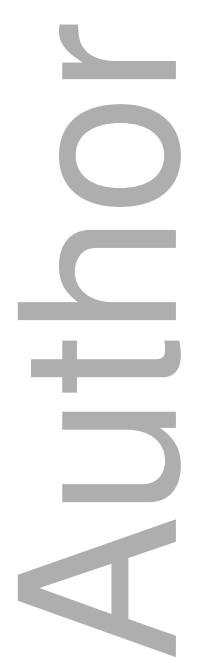



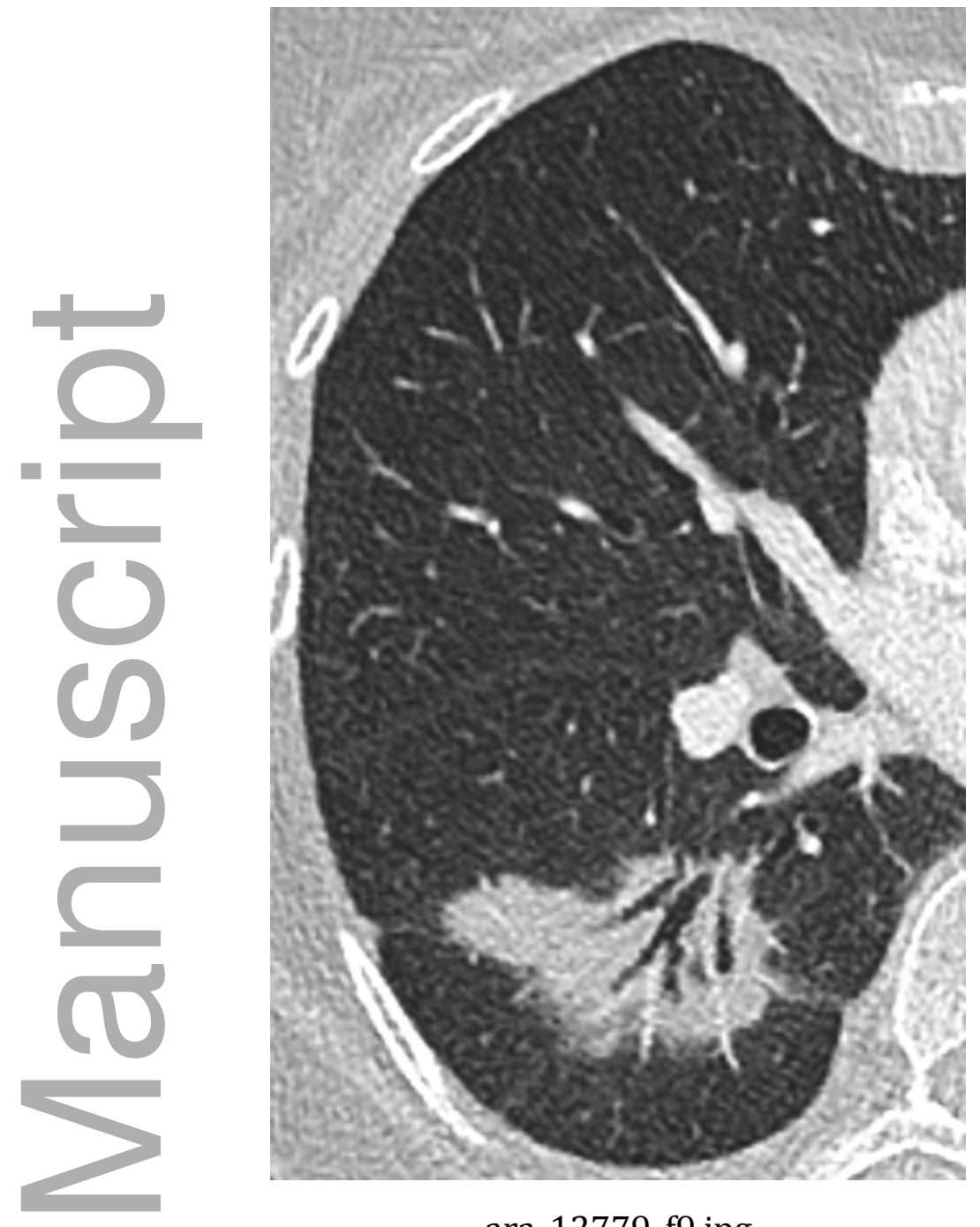

ara_12779_f9.jpg

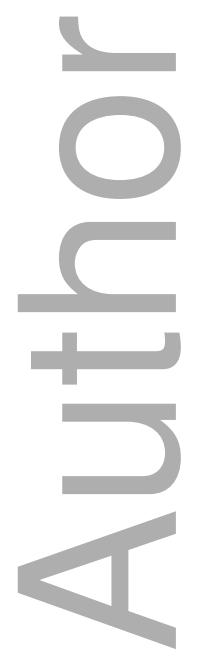



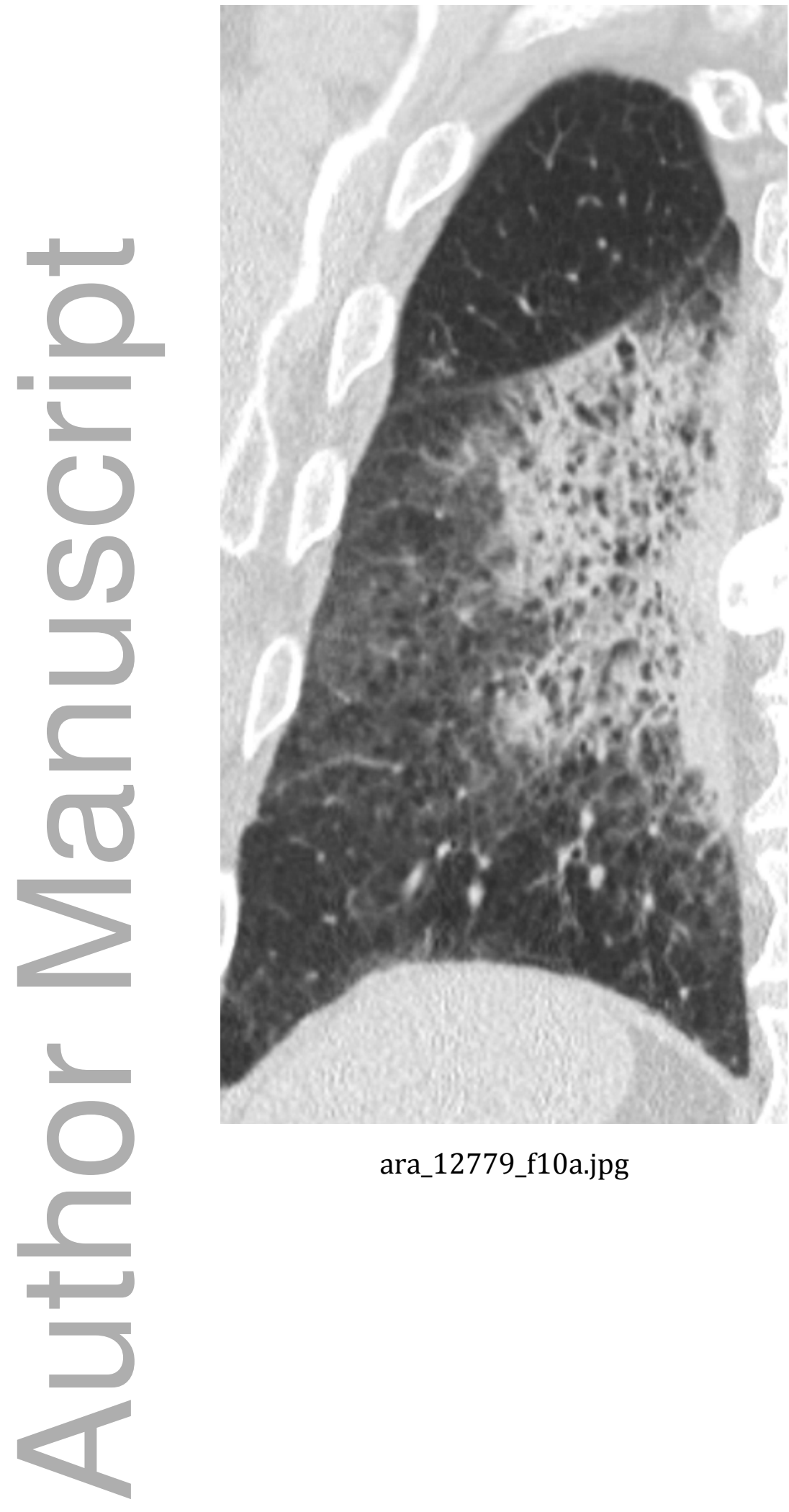

ara_12779_f10a.jpg 

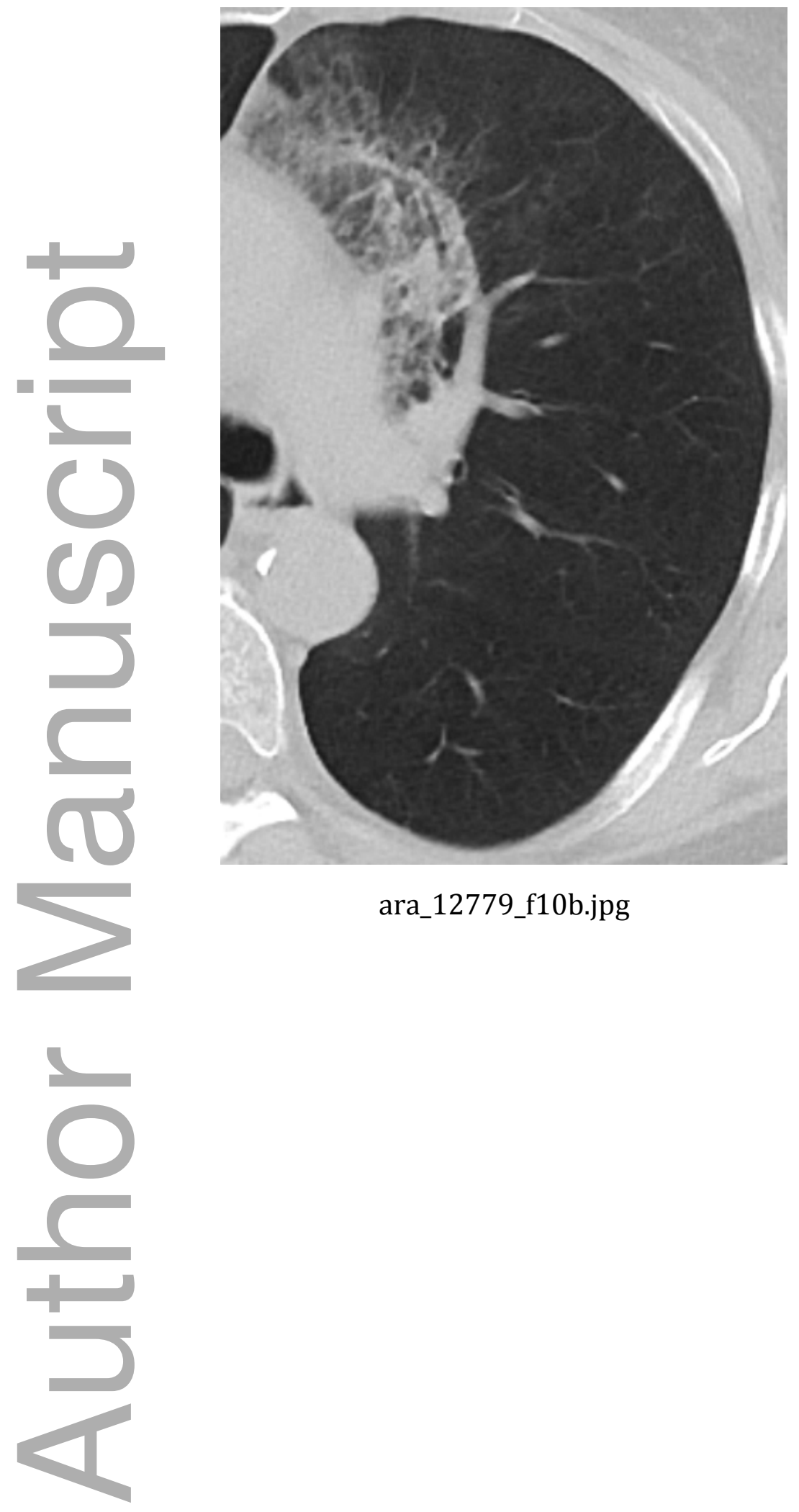

ara_12779_f10b.jpg 

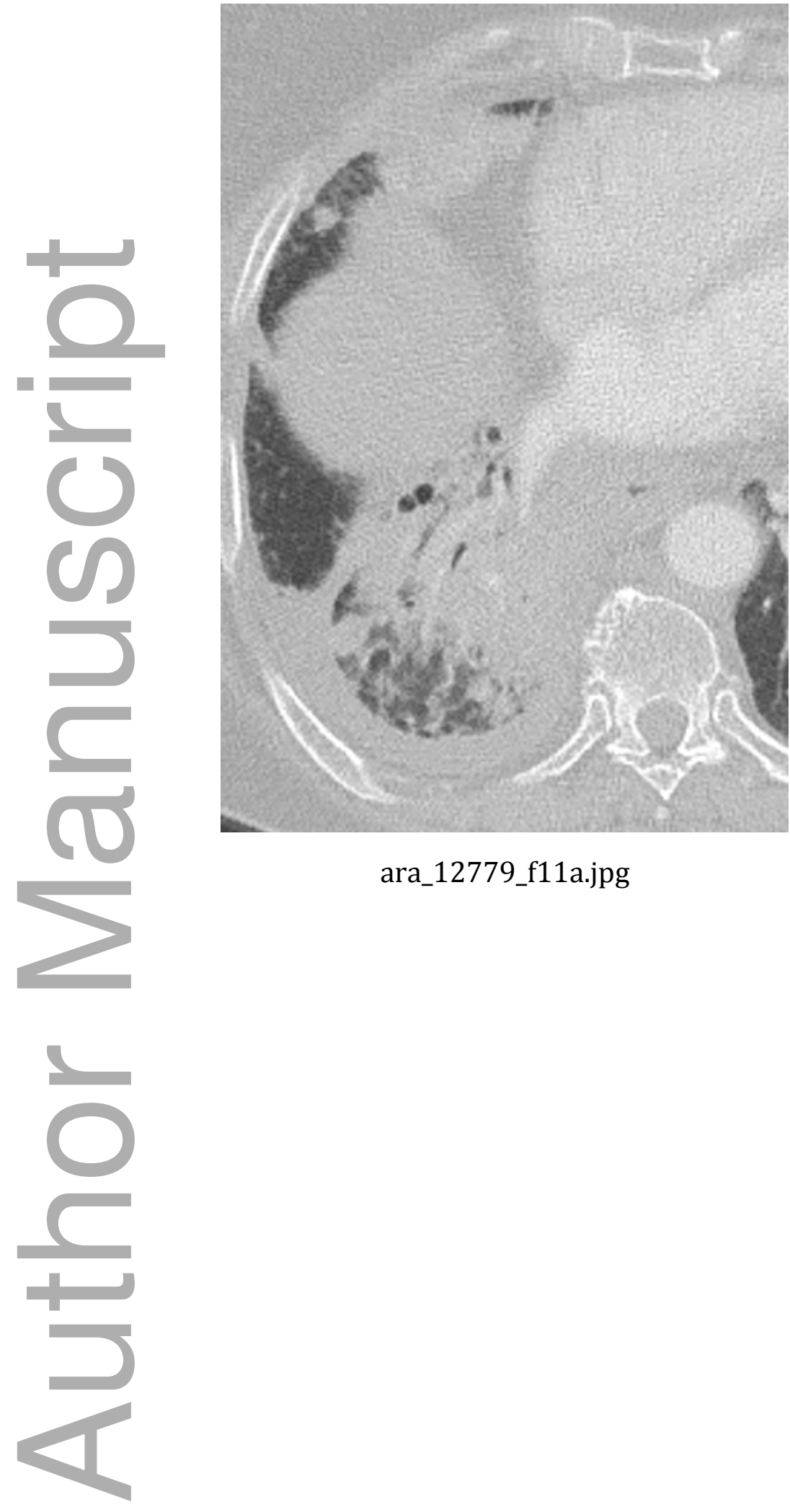

ara_12779_f11a.jpg 


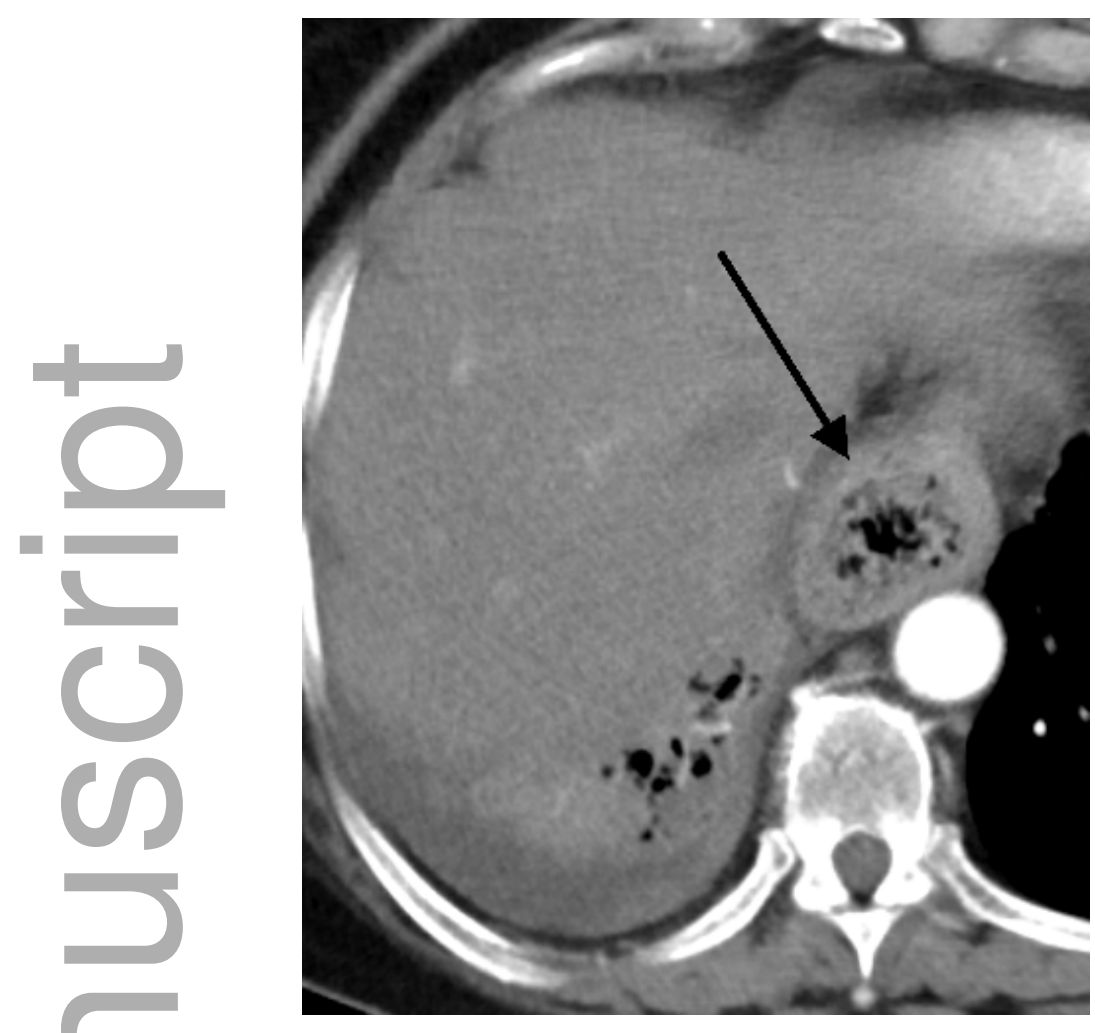

ara_12779_f11b.jpg
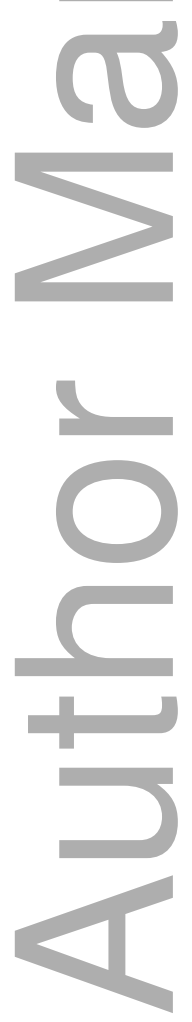

This article is protected by copyright. All rights reserved 

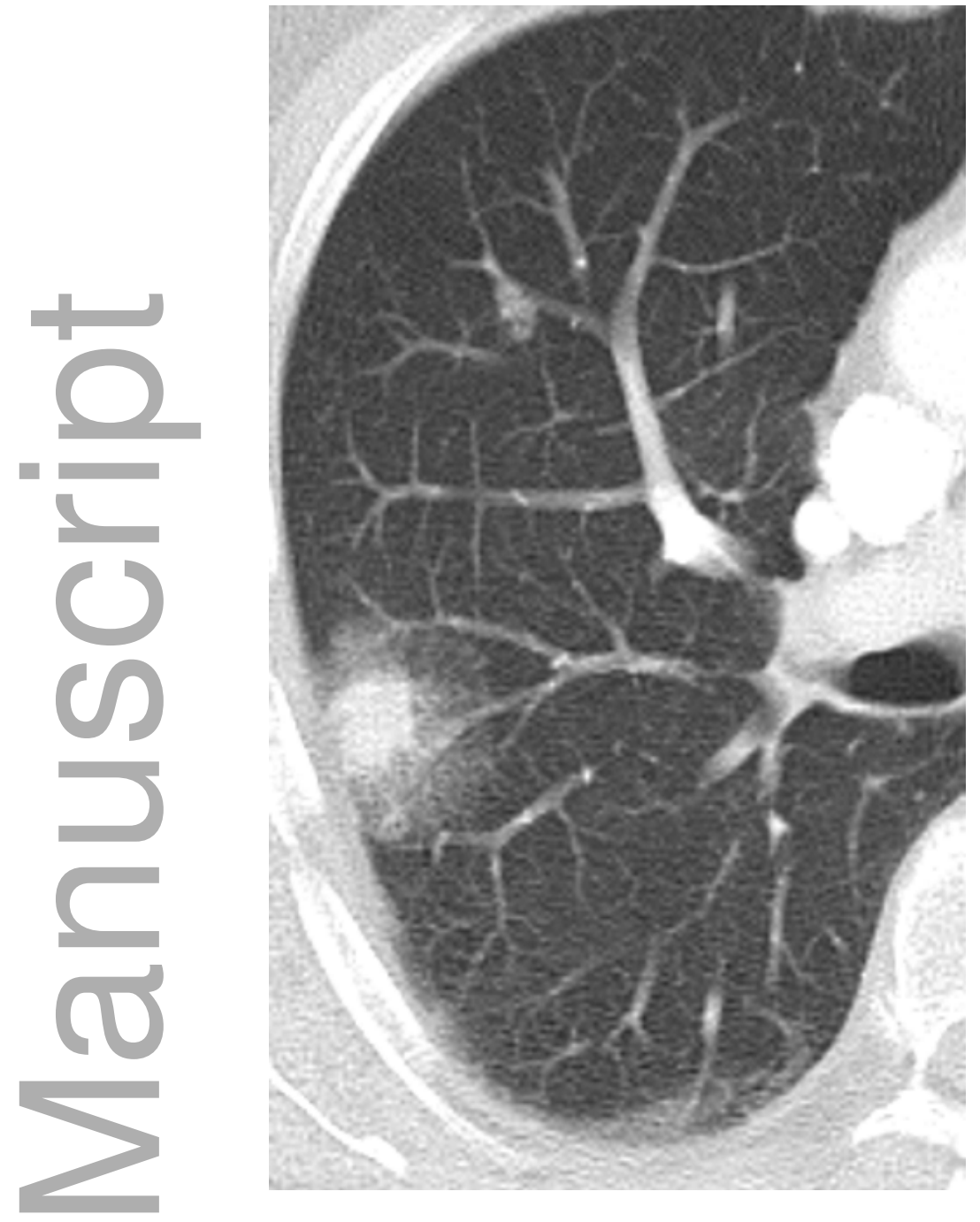

ara_12779_f12.jpg

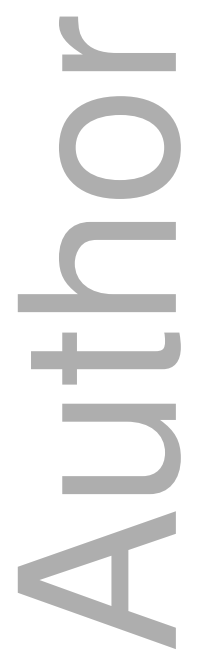



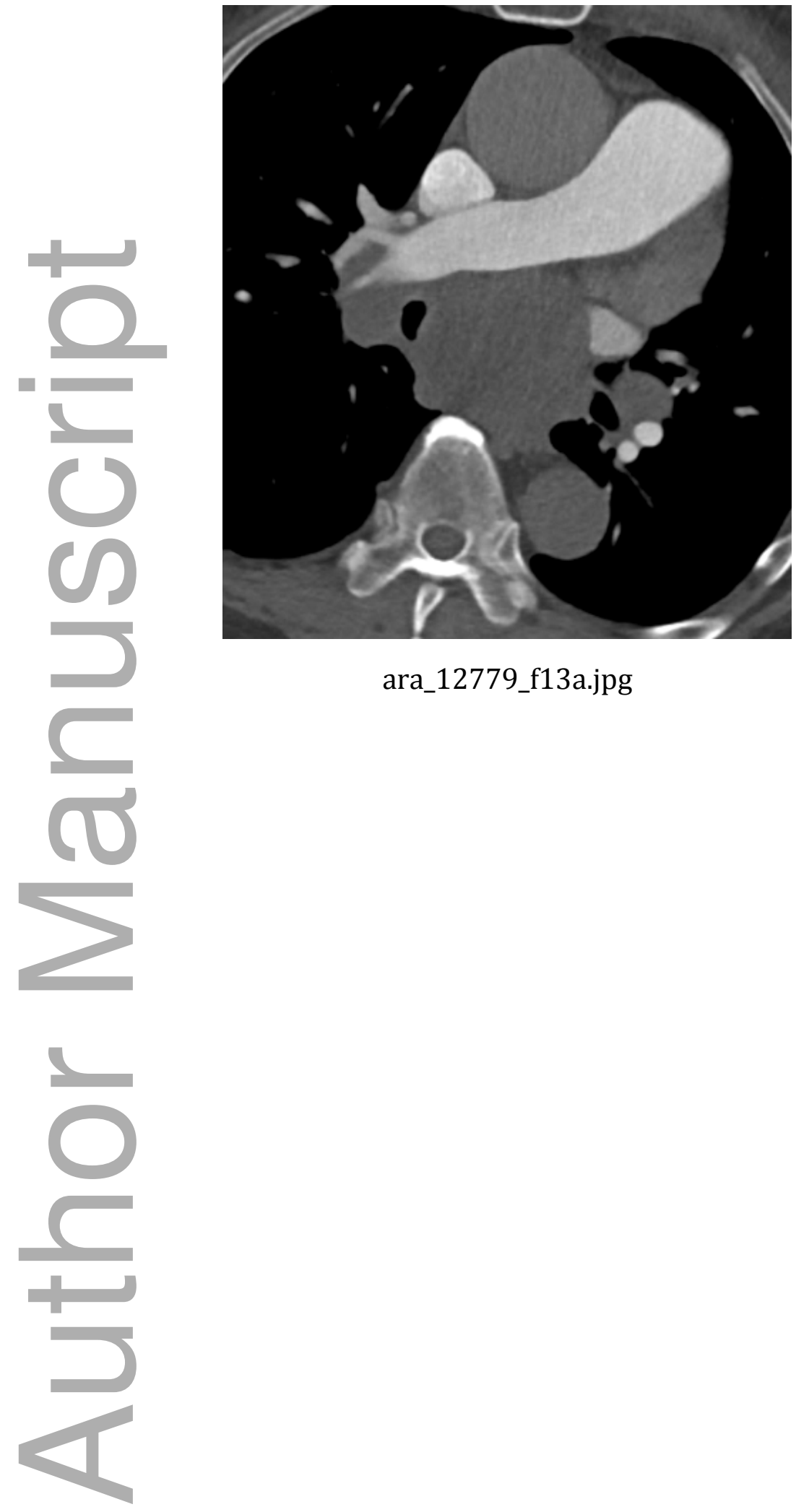

ara_12779_f13a.jpg 

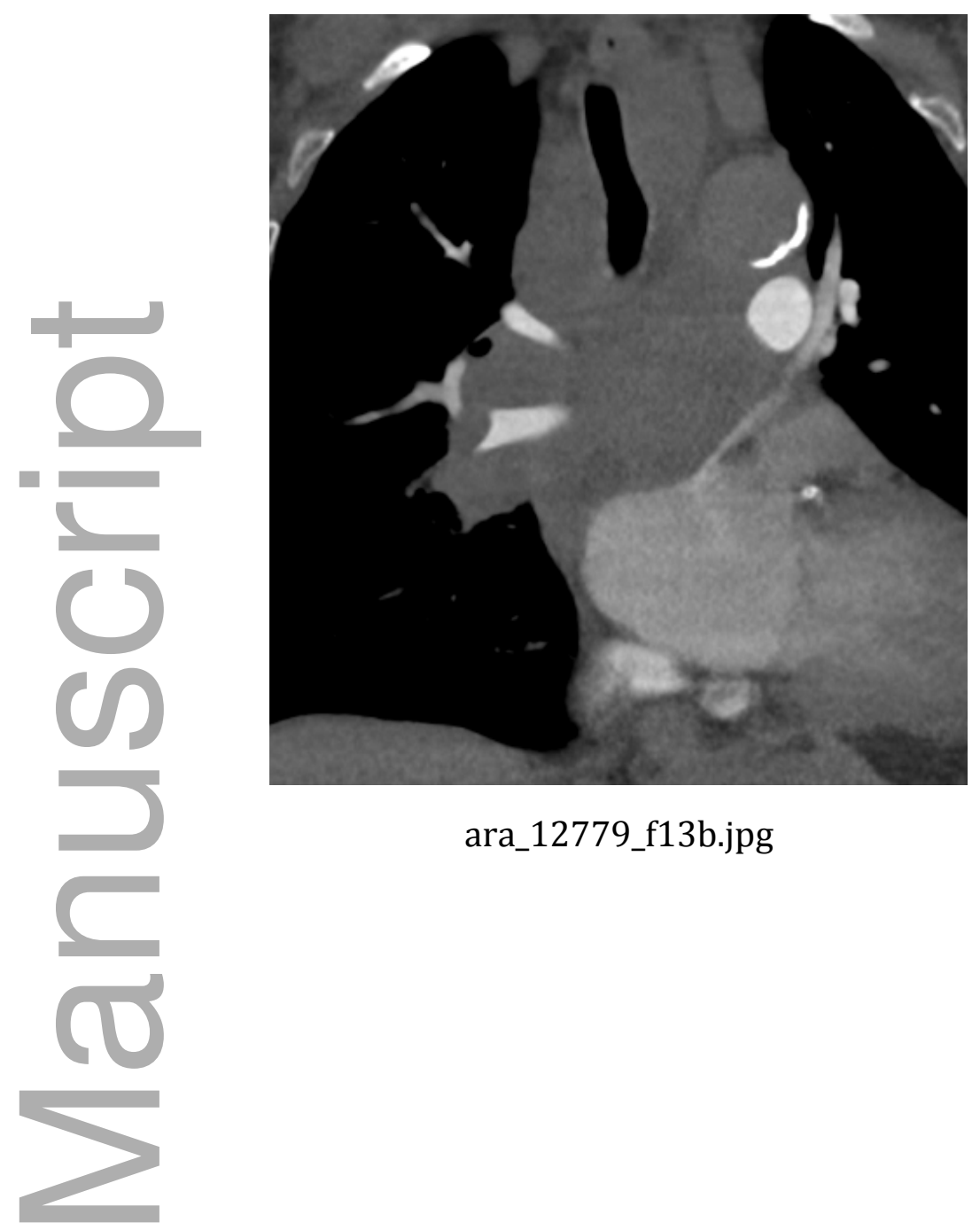

ara_12779_f13b.jpg

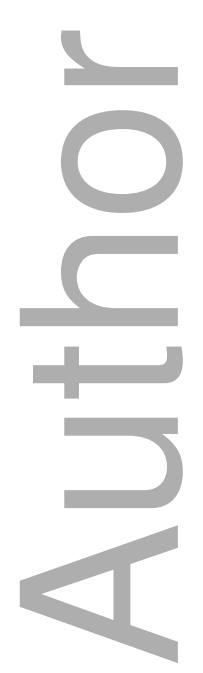



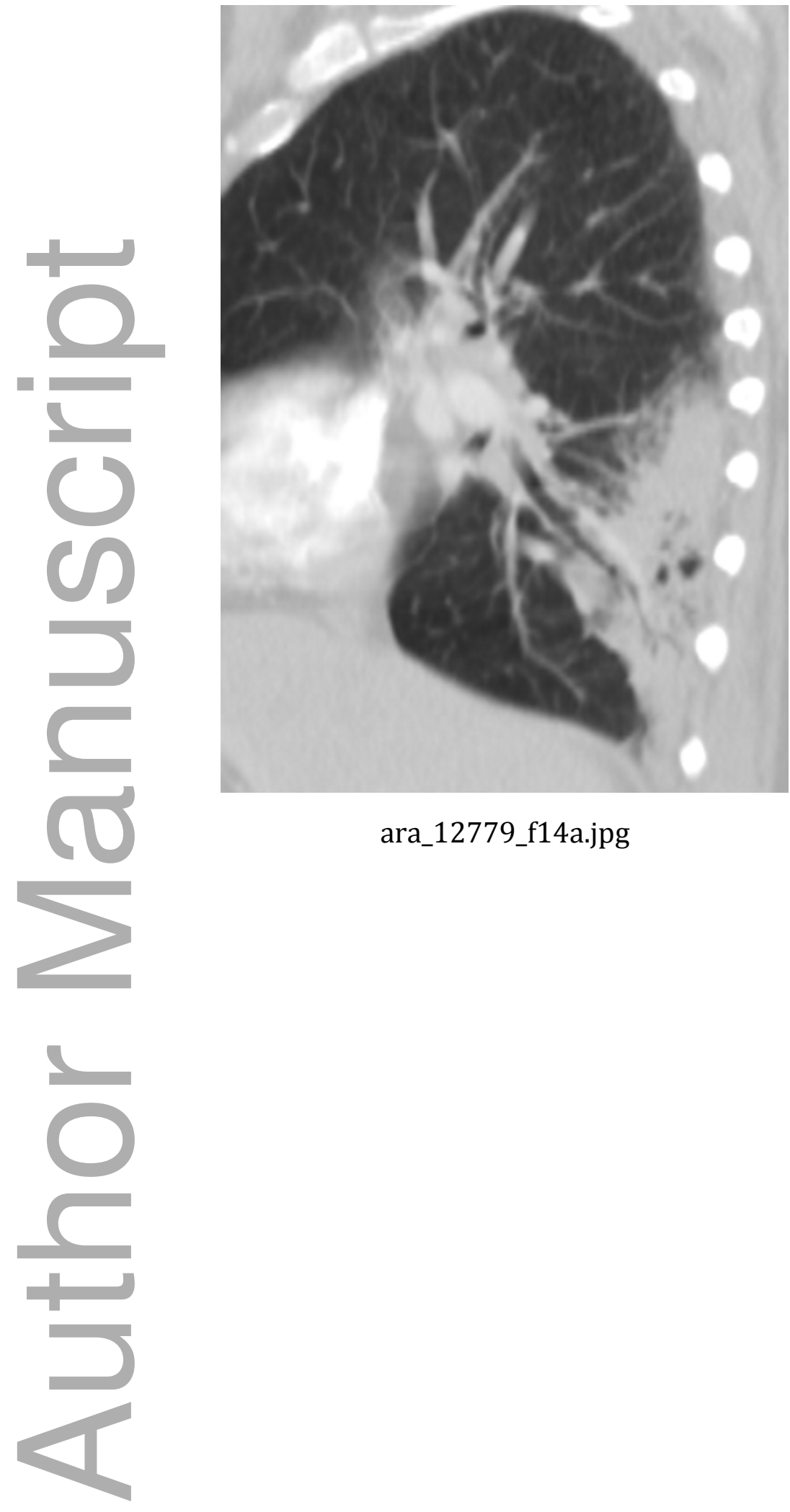

ara_12779_f14a.jpg 

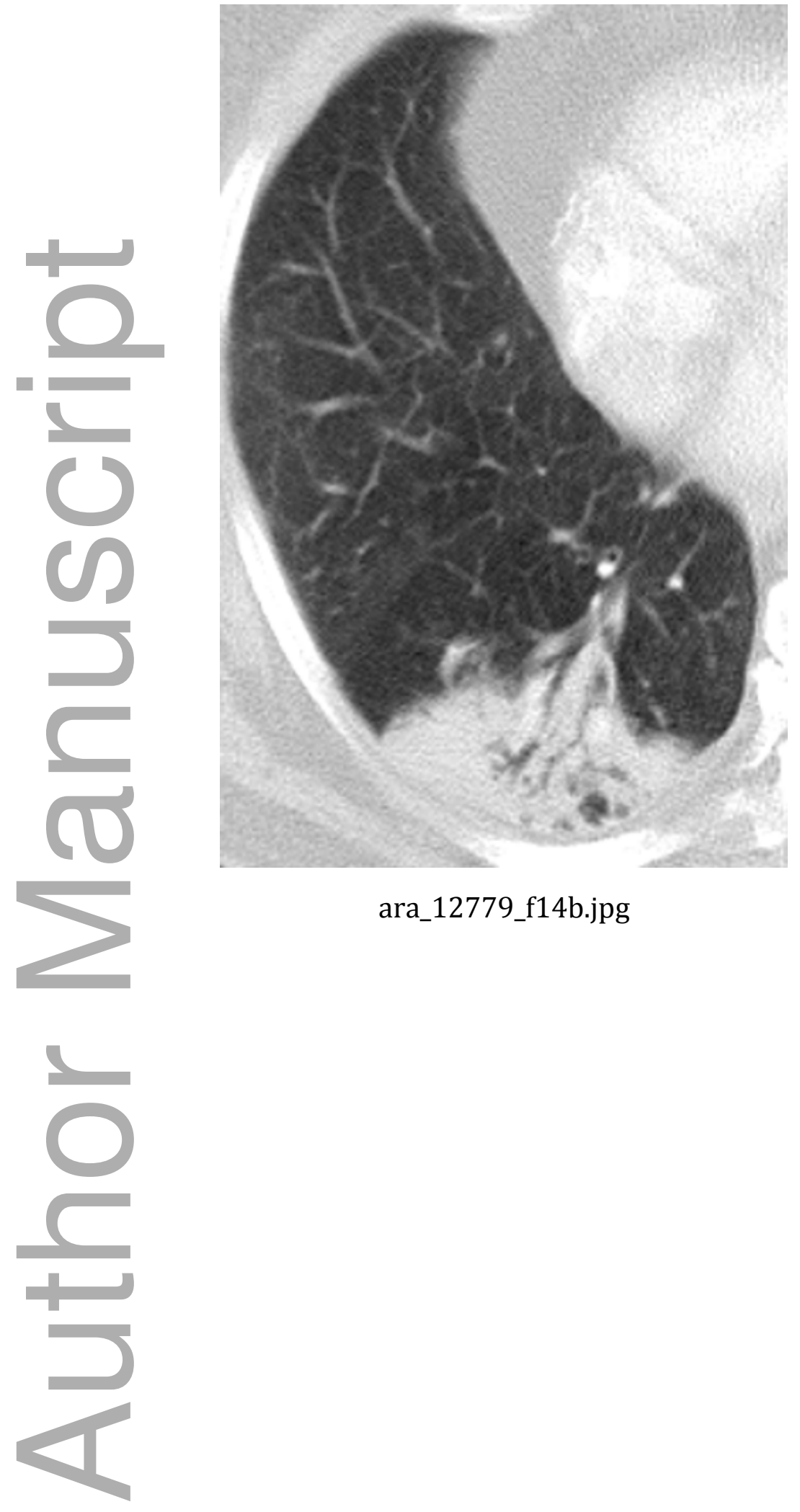

ara_12779_f14b.jpg 

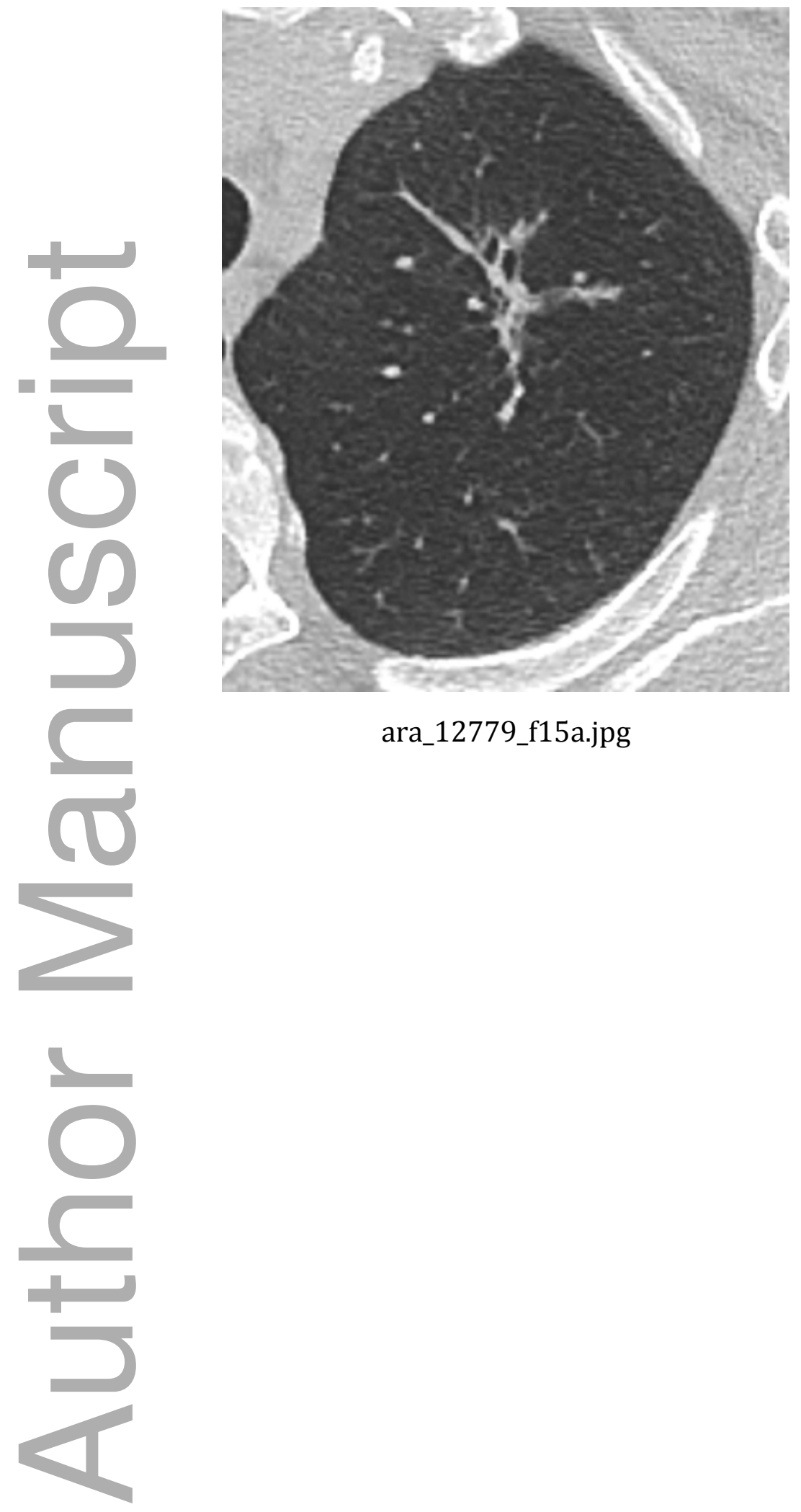

ara_12779_f15a.jpg 

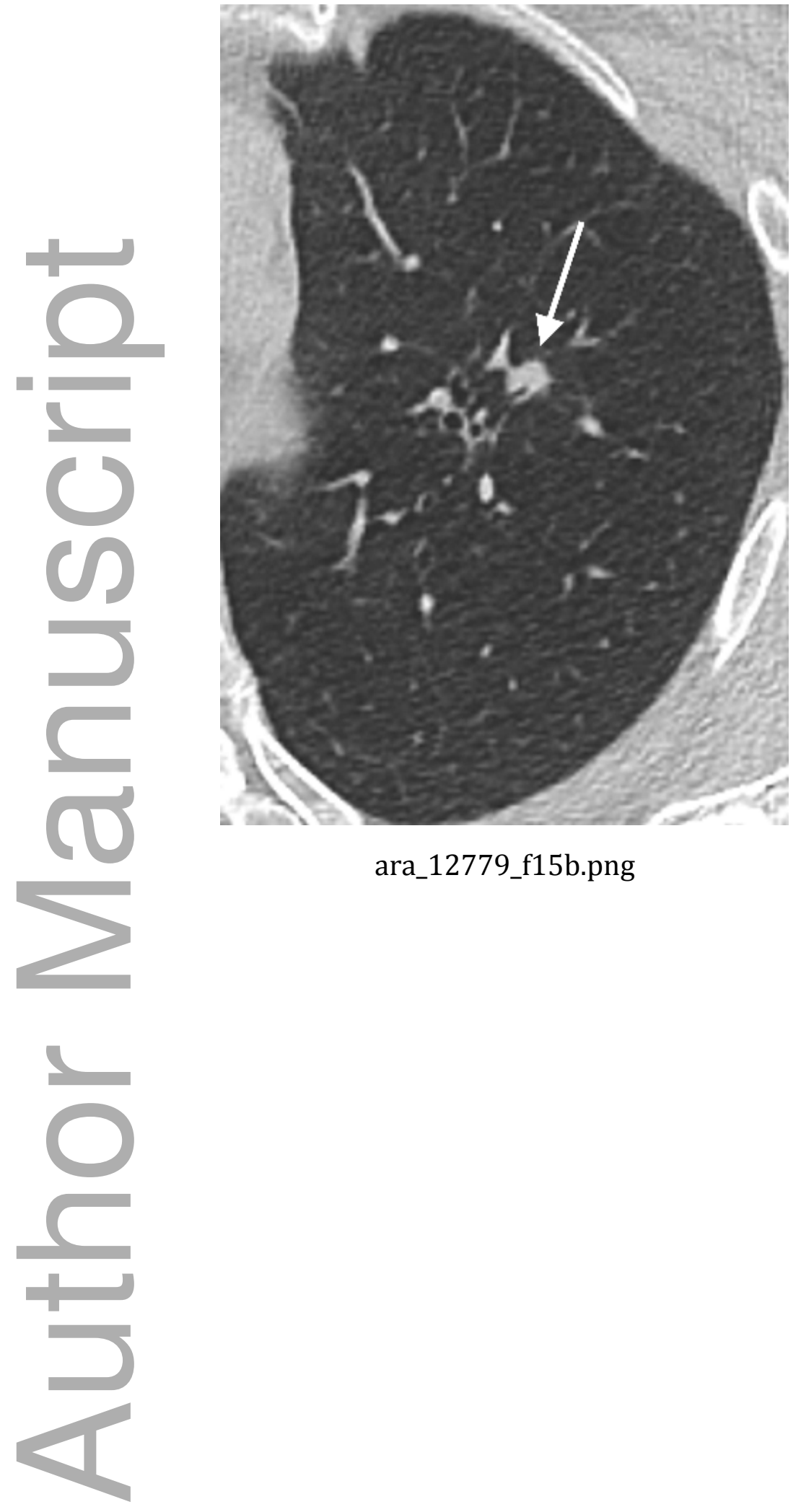

This article is protected by copyright. All rights reserved 


\section{University Library}

\section{- M M I E E R VA A gateway to Melbourne's research publications}

Minerva Access is the Institutional Repository of The University of Melbourne

Author/s:

Pascoe, HM;Knipe, HC;Pascoe, D;Heinze, SB

Title:

The many faces of lung adenocarcinoma: A pictorial essay

Date:

2018-10-01

Citation:

Pascoe, H. M., Knipe, H. C., Pascoe, D. \& Heinze, S. B. (2018). The many faces of lung adenocarcinoma: A pictorial essay. JOURNAL OF MEDICAL IMAGING AND RADIATION ONCOLOGY, 62 (5), pp.654-661. https://doi.org/10.1111/1754-9485.12779.

Persistent Link:

http://hdl.handle.net/11343/284366 